Total Synthesis of ( \pm )-Phomactin B2 via an Intramolecular Cyclohexadienone Annulation of a Chromium Carbene Complex.

\author{
Jie Huang, Chunrui Wu and William D. Wulff* \\ Department of Chemistry, Michigan State University, East Lansing MI 48824
}




\section{Spectra of New Compounds}

${ }^{1} \mathrm{H}$ NMR Spectrum of Compound 23.

${ }^{13} \mathrm{C}$ NMR Spectrum of Compound $23 . \quad$ S5

${ }^{1} \mathrm{H}$ NMR Spectrum of Compound 11.

${ }^{13} \mathrm{C}$ NMR Spectrum of Compound 11.

${ }^{1} \mathrm{H}$ NMR Spectrum of Compound 12.

${ }^{13} \mathrm{C}$ NMR Spectrum of Compound 12.

${ }^{1} \mathrm{H}$ NMR Spectrum of Compound 24 .

${ }^{13} \mathrm{C}$ NMR Spectrum of Compound $24 . \quad \mathrm{S} 11$

${ }^{1} \mathrm{H}$ NMR Spectrum of Alcohol $13 . \quad S 12$

${ }^{13} \mathrm{C}$ NMR Spectrum of Alcohol 13.

${ }^{1} \mathrm{H}$ NMR Spectrum of TIPS ether 14a. $\quad \mathrm{S} 14$

${ }^{13} \mathrm{C}$ NMR Spectrum of TIPS ether 14a. $\quad \mathrm{S} 15$

${ }^{1} \mathrm{H}$ NMR Spectrum of MOM ether 14b. $\quad$ S16

${ }^{13} \mathrm{C}$ NMR Spectrum of MOM ether 14b. $\quad \mathrm{S} 17$

${ }^{1} \mathrm{H}$ NMR Spectrum of Carbene Complex 3a. S18

${ }^{13} \mathrm{C}$ NMR Spectrum of Carbene Complex 3a. $\quad \mathrm{S} 19$

${ }^{1} \mathrm{H}$ NMR Spectrum of Carbene Complex $\mathbf{3 b}$. $\quad$ S20

${ }^{13} \mathrm{C}$ NMR Spectrum of Carbene Complex 3b. S21

${ }^{1} \mathrm{H}$ NMR Spectrum of Dienone $\mathbf{2 a}$. S22

${ }^{13} \mathrm{C}$ NMR Spectrum of Dienone 2a. S23

${ }^{1} \mathrm{H}$ NMR Spectrum of Dienone 2b. $\quad$ S24

${ }^{13} \mathrm{C}$ NMR Spectrum of Dienone $\mathbf{2 b} . \quad$ S25

${ }^{1} \mathrm{H}$ NMR Spectrum of Dienone 15a. $\quad$ S26

${ }^{13} \mathrm{C}$ NMR Spectrum of Dienone 15a. $\quad$ S27

${ }^{1} \mathrm{H}$ NMR Spectrum of Dienone 15b. S28

${ }^{13} \mathrm{C}$ NMR Spectrum of Dienone 15b. S29

${ }^{1} \mathrm{H}$ NMR Spectrum of Dienone 2c. $\quad$ S30

${ }^{13} \mathrm{C}$ NMR Spectrum of Dienone 2c. S31

${ }^{1} \mathrm{H}$ NMR Spectrum of Dienone 16.

${ }^{13} \mathrm{C}$ NMR Spectrum of Dienone 16.

${ }^{1} \mathrm{H}$ NMR Spectrum of Dienone $25 . \quad$ S34

${ }^{13} \mathrm{C}$ NMR Spectrum of Dienone 25.

${ }^{1} \mathrm{H}$ NMR Spectrum of Keto Alcohol $26 . \quad$ S36

${ }^{13} \mathrm{C}$ NMR Spectrum of Keto Alcohol $26 . \quad$ S37 
${ }^{1} \mathrm{H}$ NMR Spectrum of TIPS ether 27 . S38

${ }^{13} \mathrm{C}$ NMR Spectrum of TIPS ether $27 . \quad$ S39

${ }^{1} \mathrm{H}$ NMR Spectrum of Allylic Alcohol 18.

${ }^{13} \mathrm{C}$ NMR Spectrum of Alylic Alcohol 18.

${ }^{1} \mathrm{H}$ NMR Spectrum of Allylic Alcohol 19.

${ }^{13} \mathrm{C}$ NMR Spectrum of Allylic Alcohol 19.

${ }^{1} \mathrm{H}$ NMR Spectrum of Epoxy Alcohol 21.

${ }^{13} \mathrm{C}$ NMR Spectrum of Epoxy Alcohol $21 . \quad \$ 45$

${ }^{1} \mathrm{H}$ NMR Spectrum of Epoxy Alcohol $20 . \quad$ S46

${ }^{13} \mathrm{C}$ NMR Spectrum of Epoxy Alcohol $20 . \quad S 47$

${ }^{1} \mathrm{H}$ NMR Spectrum of Epoxy Ketone 29.

${ }^{13} \mathrm{C}$ NMR Spectrum of Epoxy Ketone 29.

${ }^{1} \mathrm{H}$ NMR Spectrum of Epoxy Ketone $22 \quad$ S50

${ }^{13} \mathrm{C}$ NMR Spectrum of Epoxy Ketone $22 \quad$ S51

${ }^{1} \mathrm{H}$ NMR Spectrum of Epoxy Ketone 22 in $\mathrm{CD}_{3} \mathrm{OD} \quad \mathrm{S} 52$

${ }^{13} \mathrm{C}$ NMR Spectrum of Epoxy Ketone 22 in $\mathrm{CD}_{3} \mathrm{OD} \quad \mathrm{S} 53$

${ }^{1} \mathrm{H}$ NMR Spectrum of Acetate $30 . \quad$ S54

${ }^{13} \mathrm{C}$ NMR Spectrum of Acetate $30 . \quad$ S55

${ }^{1} \mathrm{H}$ NMR Spectrum of Acetate $\mathbf{3 0}$ in $\mathrm{CD}_{3} \mathrm{OD} \quad$ S56

${ }^{13} \mathrm{C}$ NMR Spectrum of Acetate 30 in $\mathrm{CD}_{3} \mathrm{OD} \quad \mathrm{S} 57$

${ }^{1} \mathrm{H}$ NMR Spectrum of Phomactin B2. $\quad$ S58

${ }^{13}$ C NMR Spectrum of Phomactin B2. $\quad$ S59

${ }^{1} \mathrm{H}$ NMR Spectrum of Phomactin B2 in $\mathrm{CD}_{3} \mathrm{OD} \quad \mathrm{S} 60$

${ }^{13} \mathrm{C}$ NMR Spectrum of Phomactin $\mathrm{B} 2$ in $\mathrm{CD}_{3} \mathrm{OD} \quad \mathrm{S} 61$

${ }^{1} \mathrm{H}$ NMR Spectrum of p-Nitrobenzoate $31 . \quad S 62$

${ }^{13} \mathrm{C}$ NMR Spectrum of $p$-Nitrobenzoate 31. 


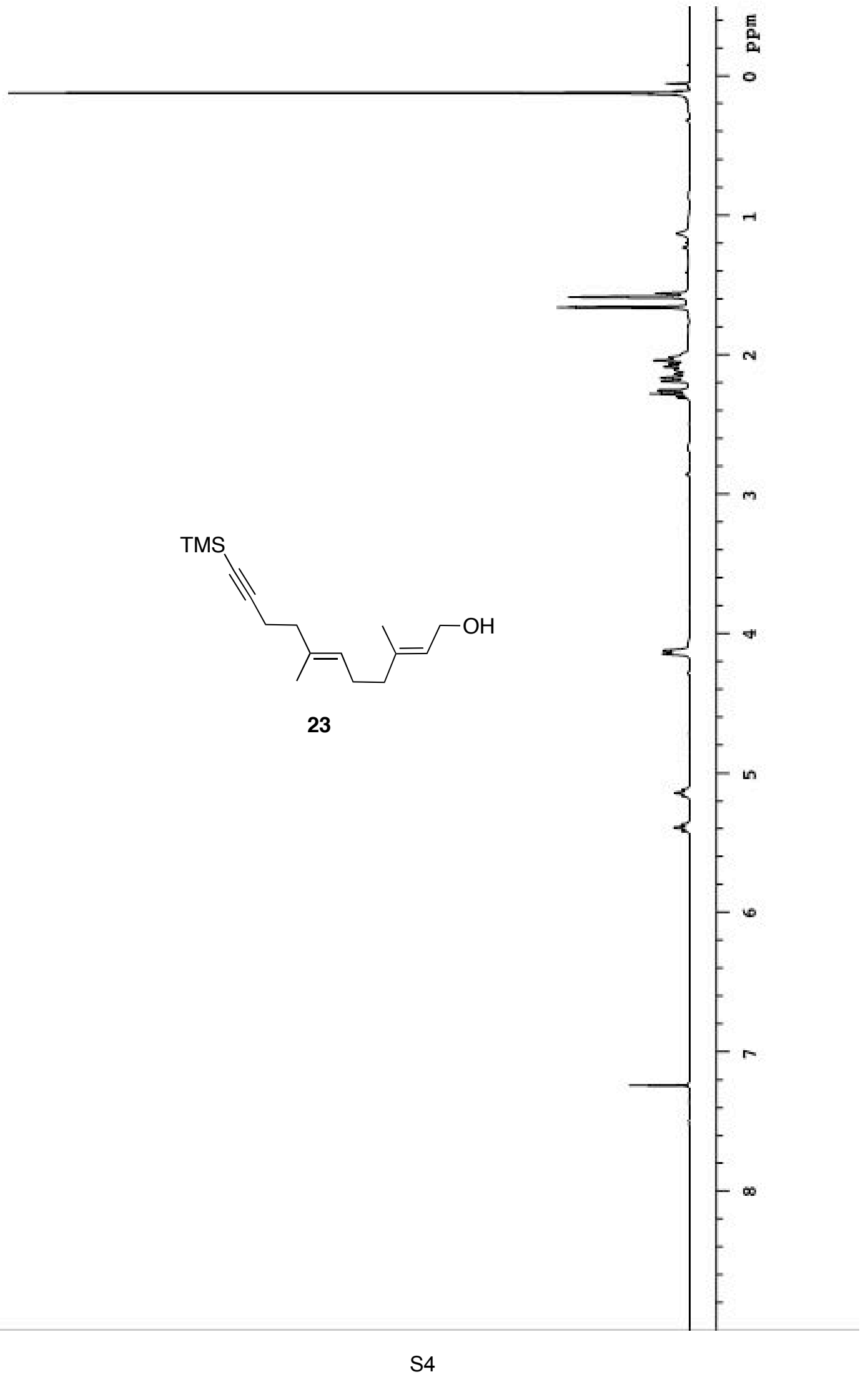




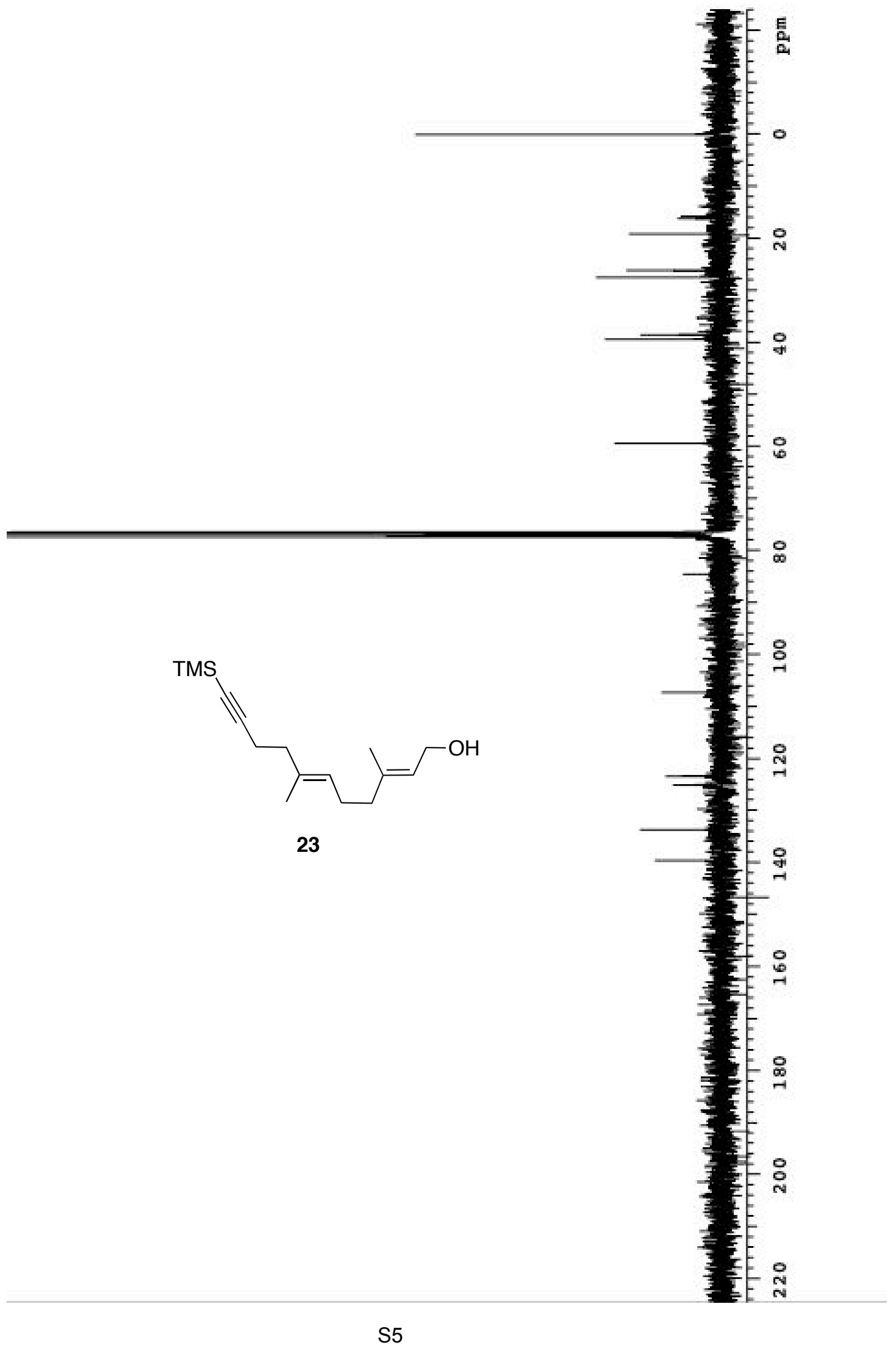




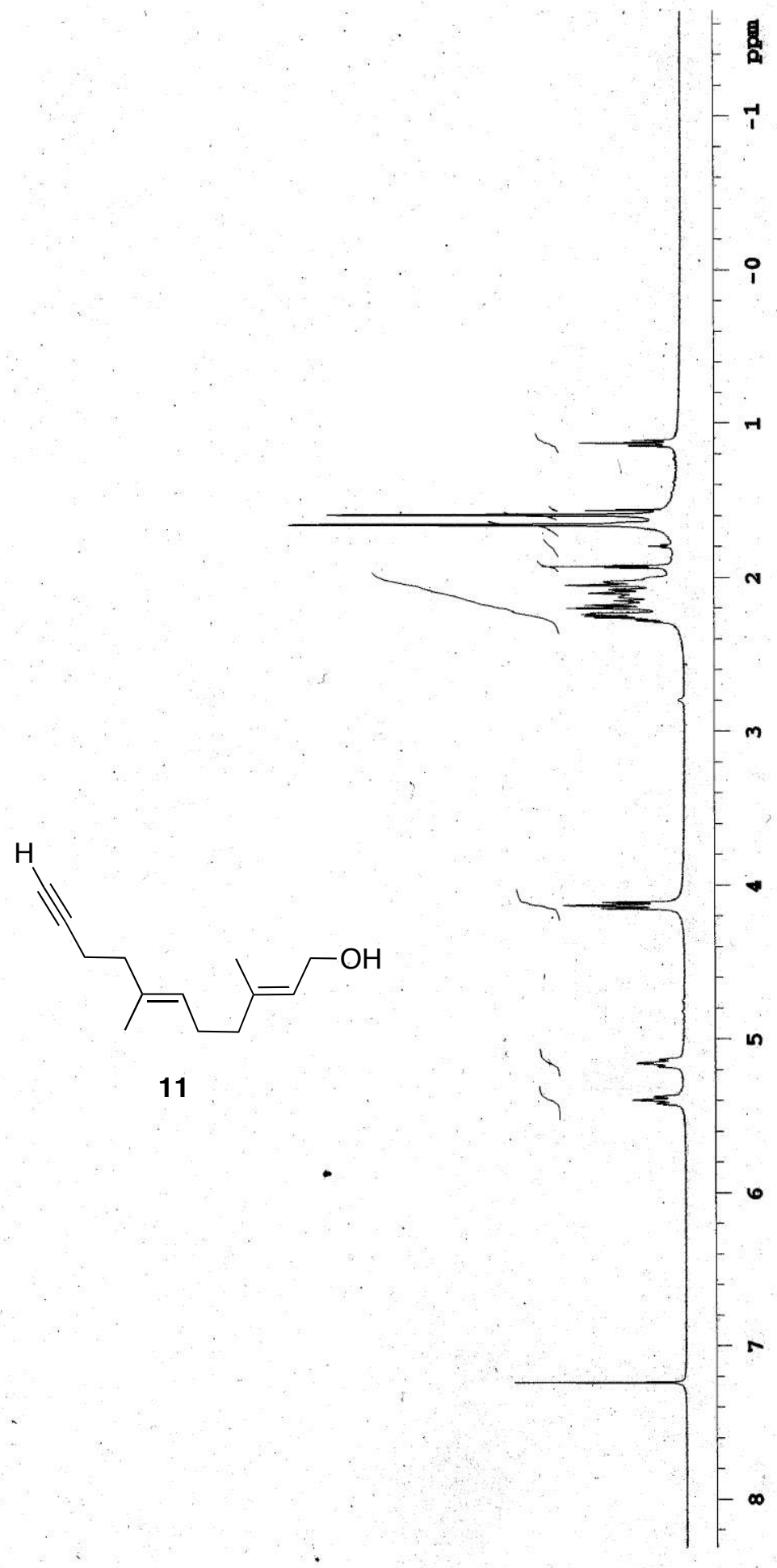




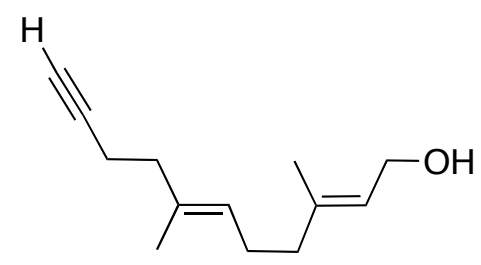

11

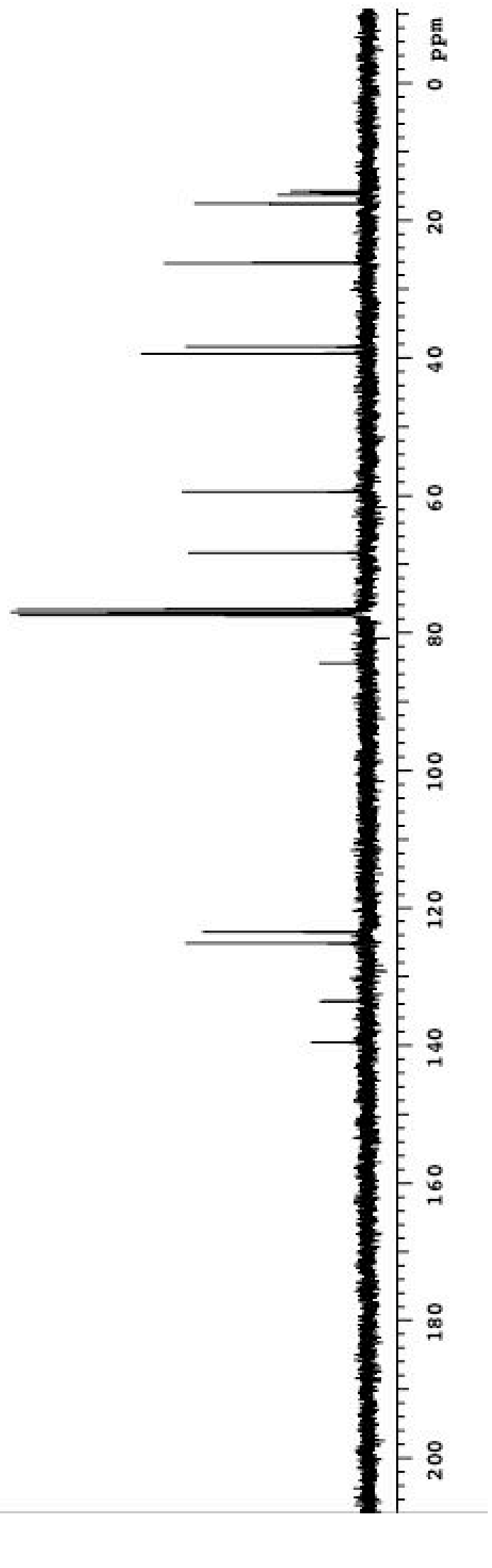




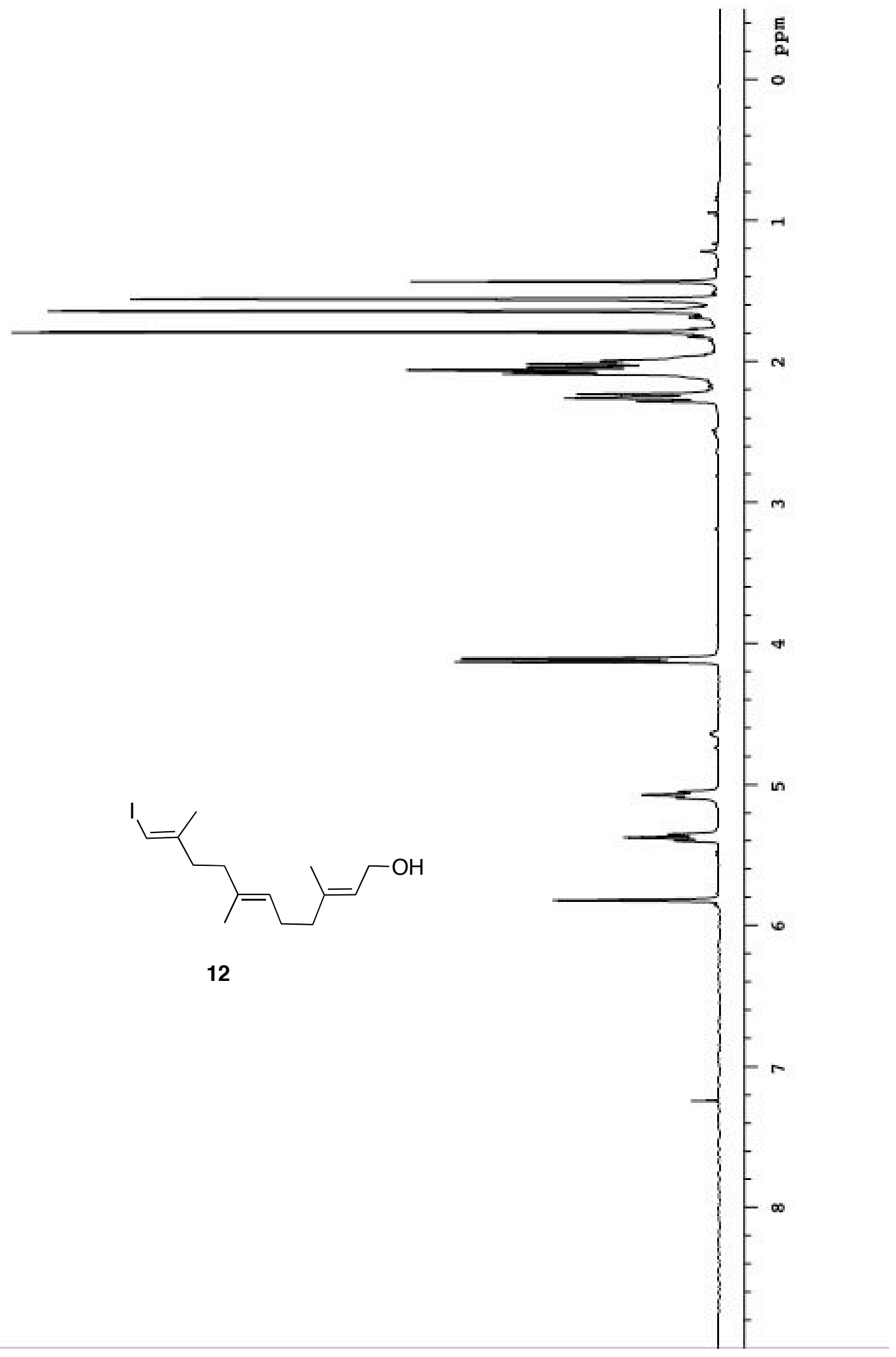




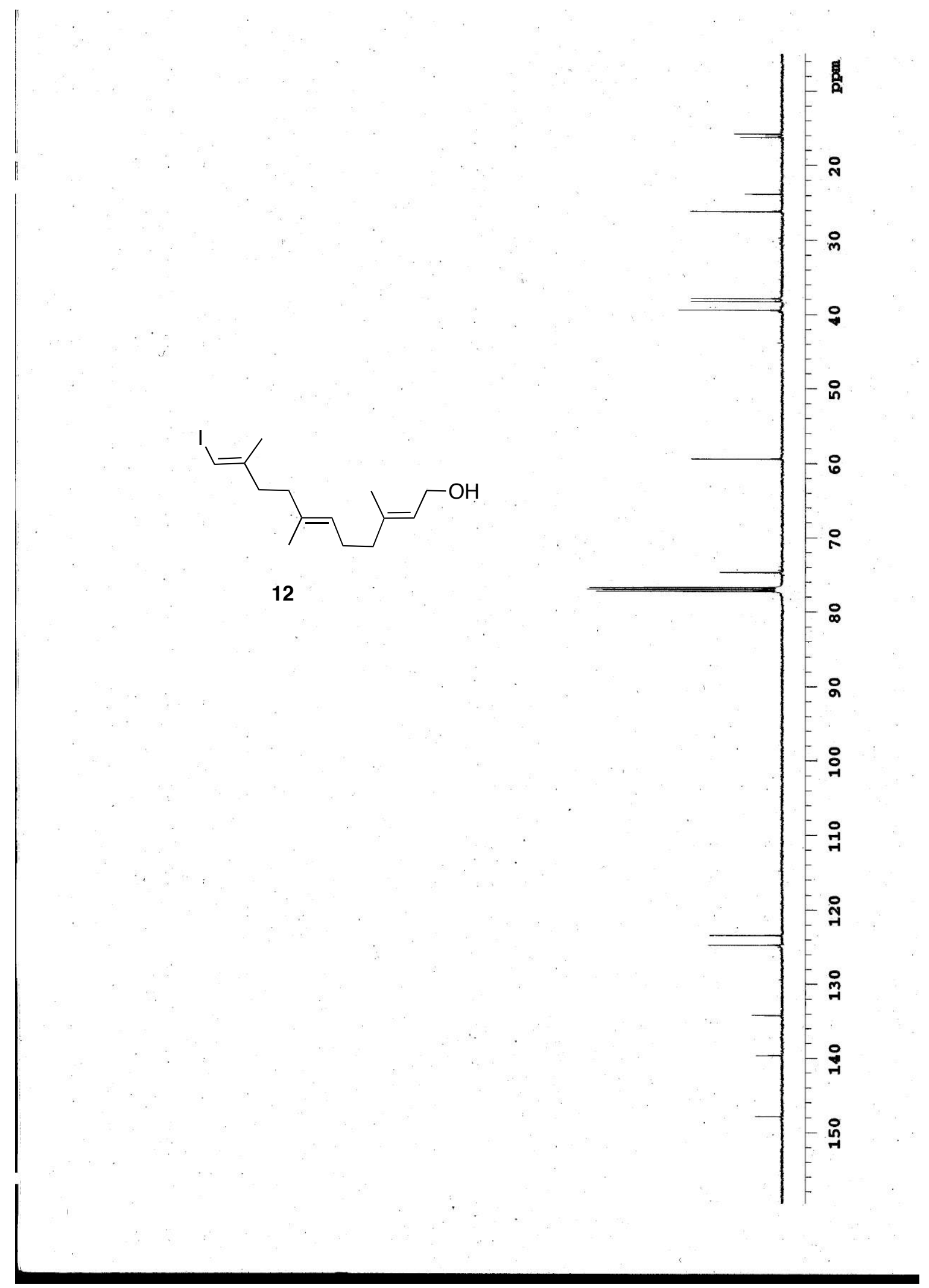




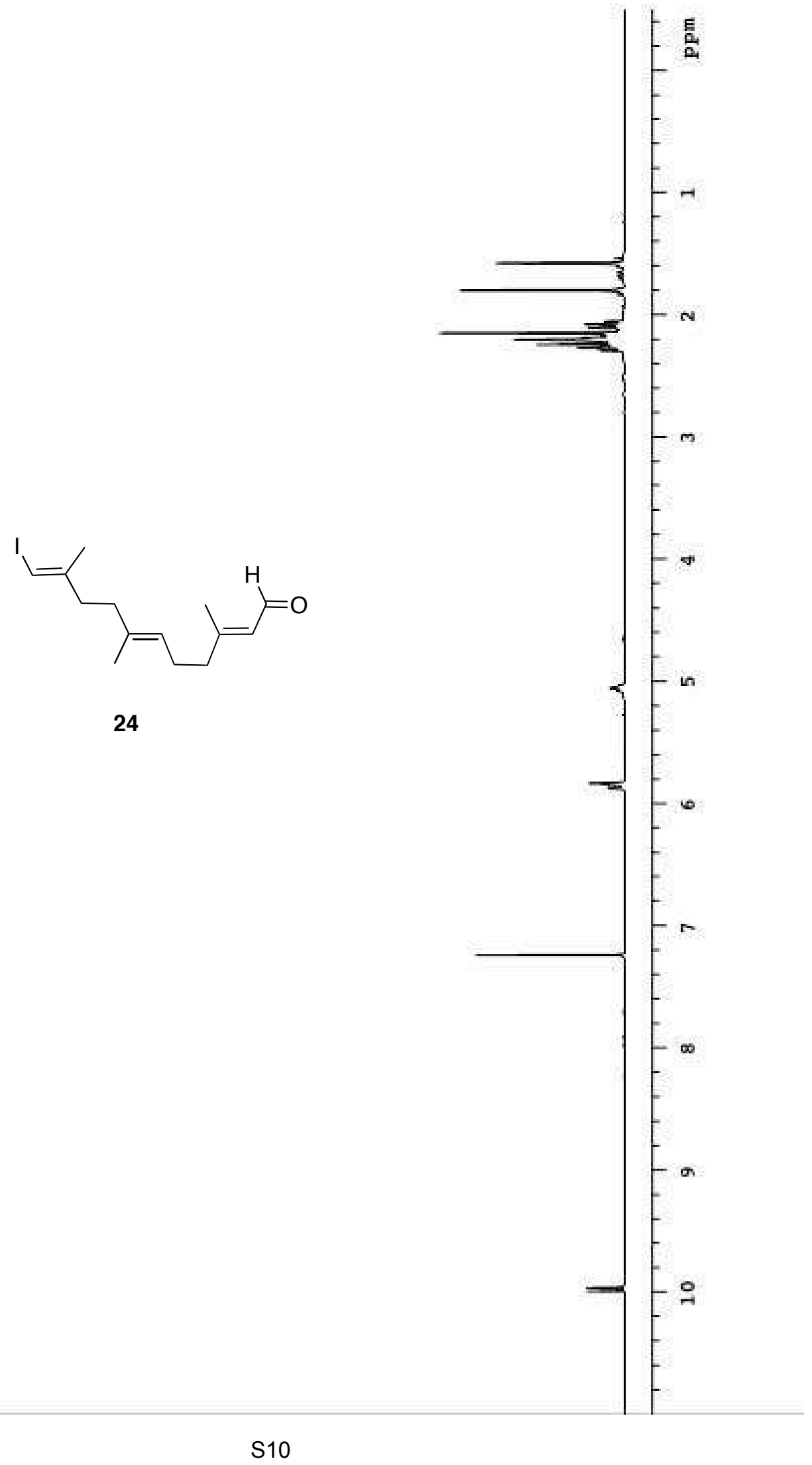



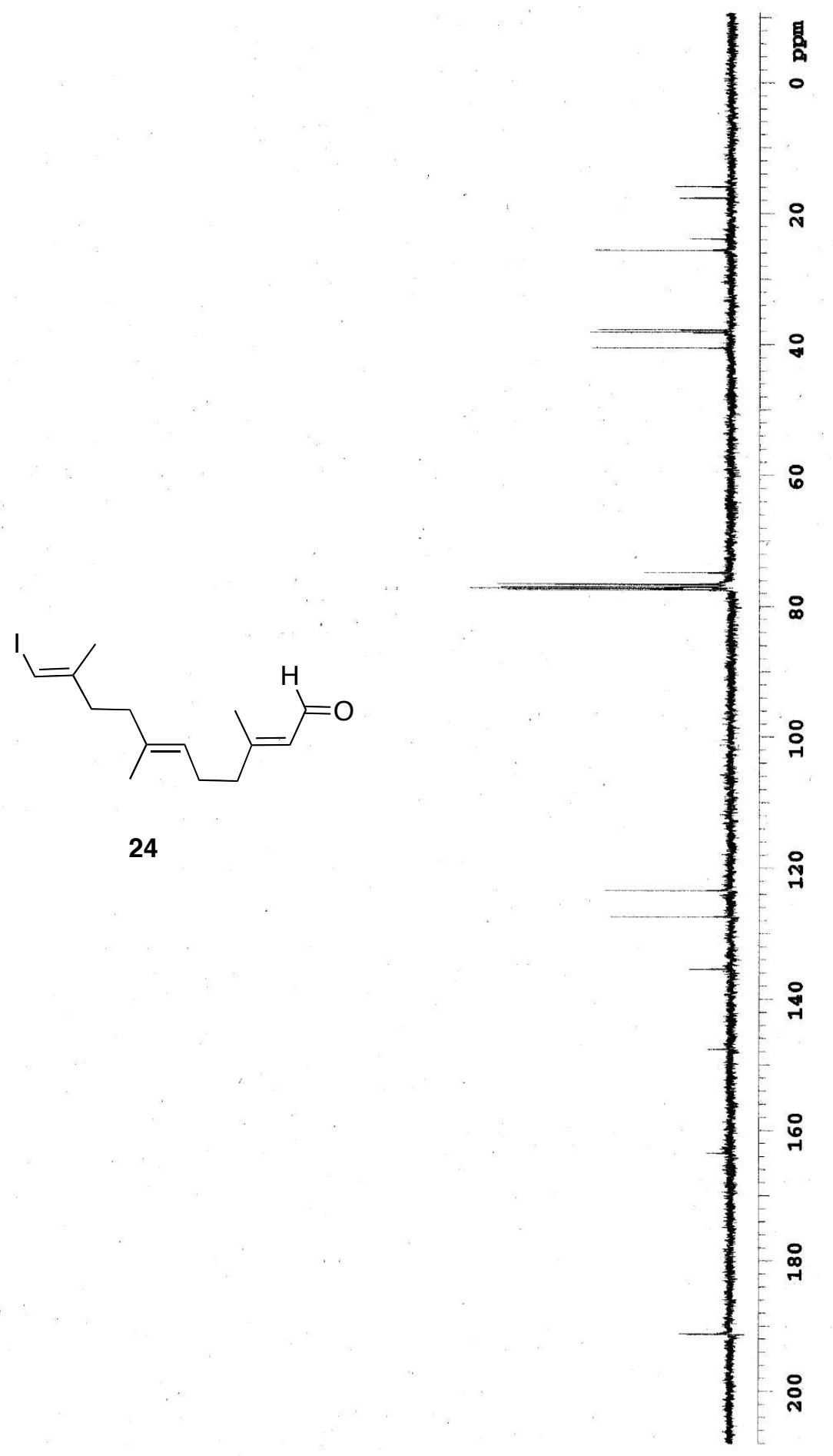

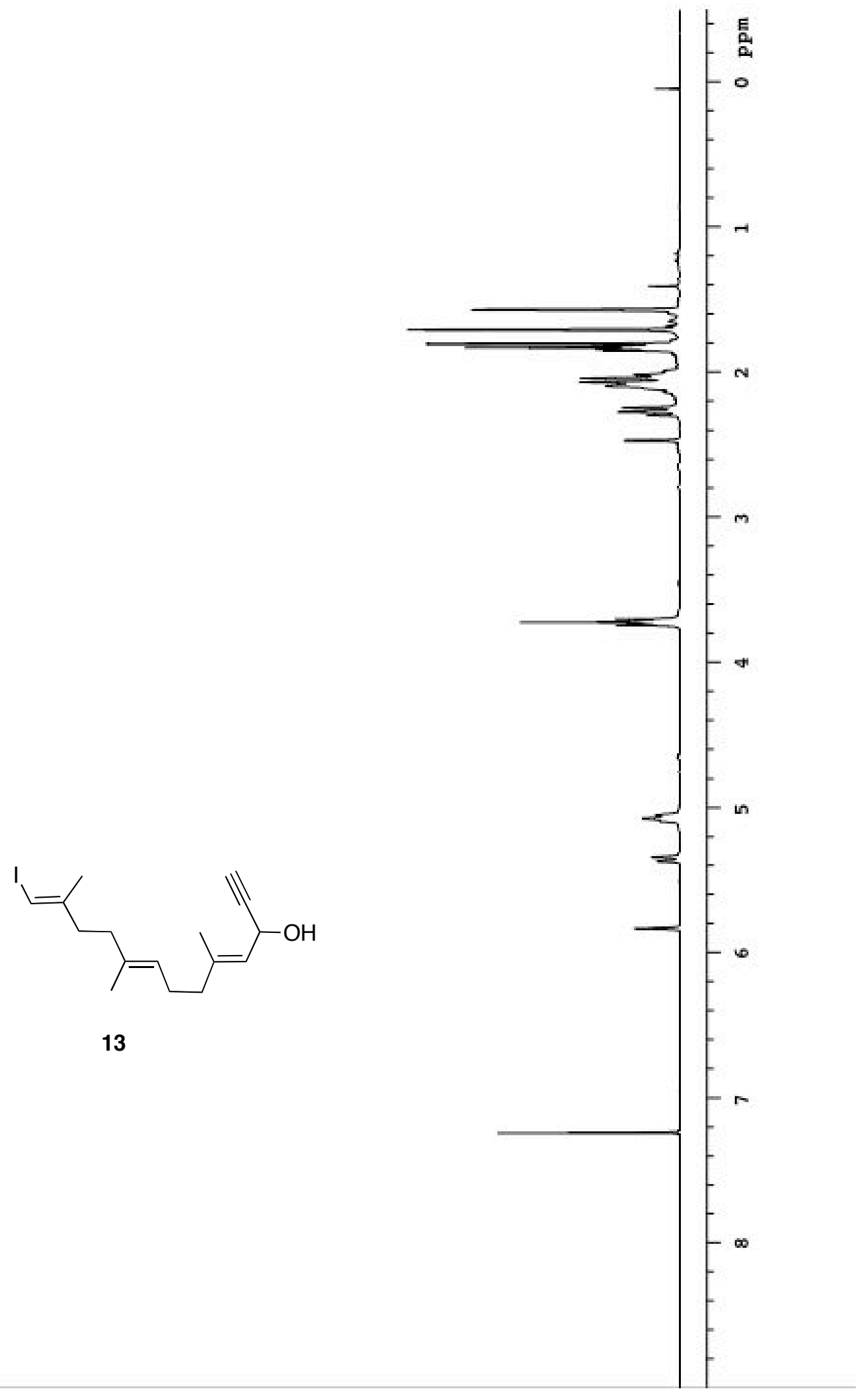


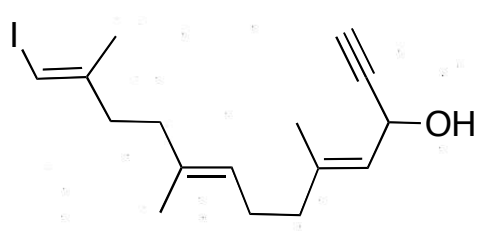

13

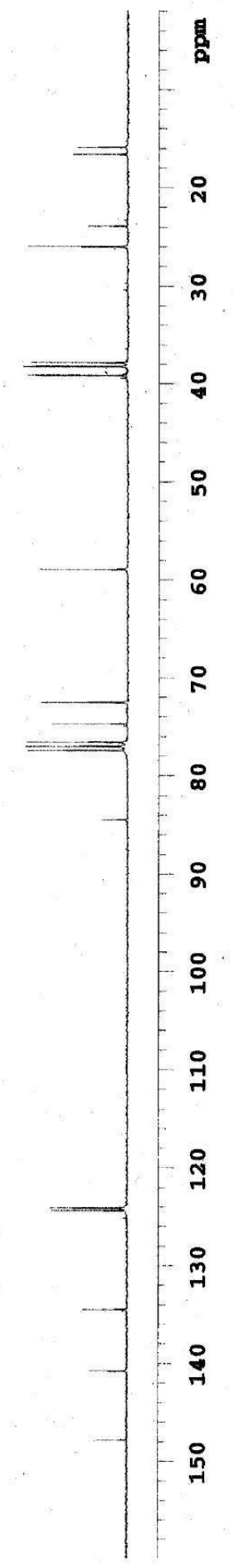




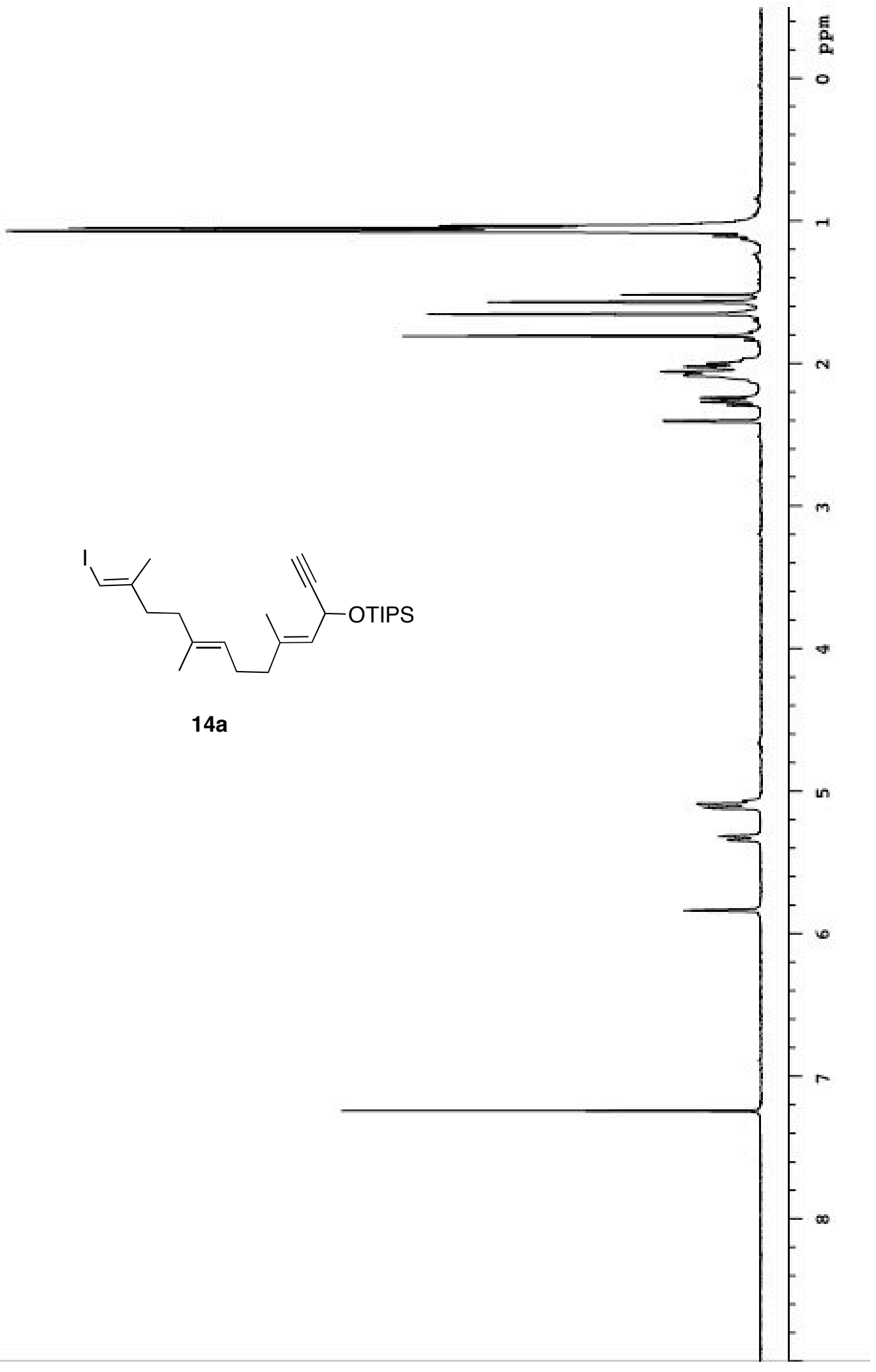




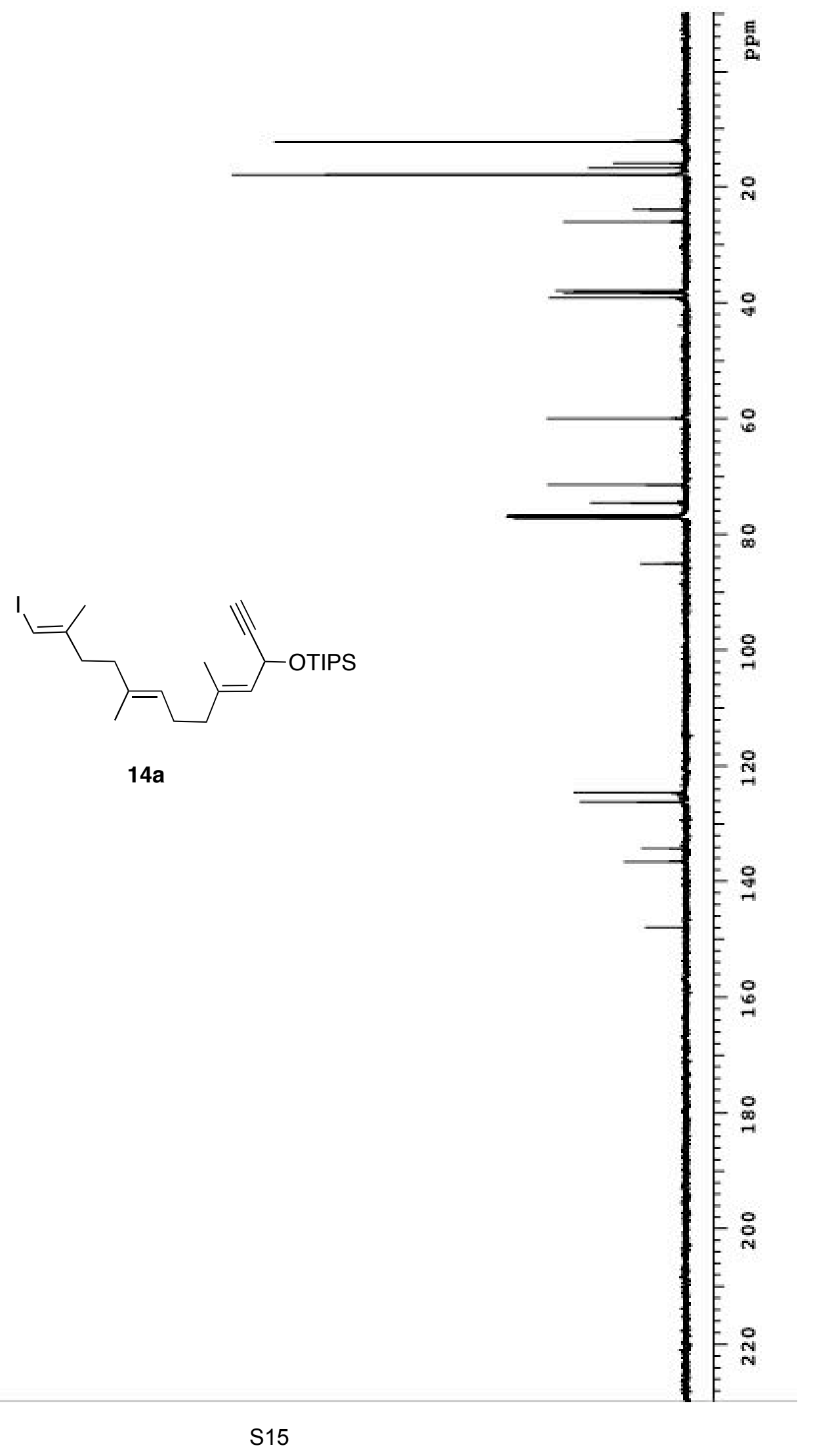




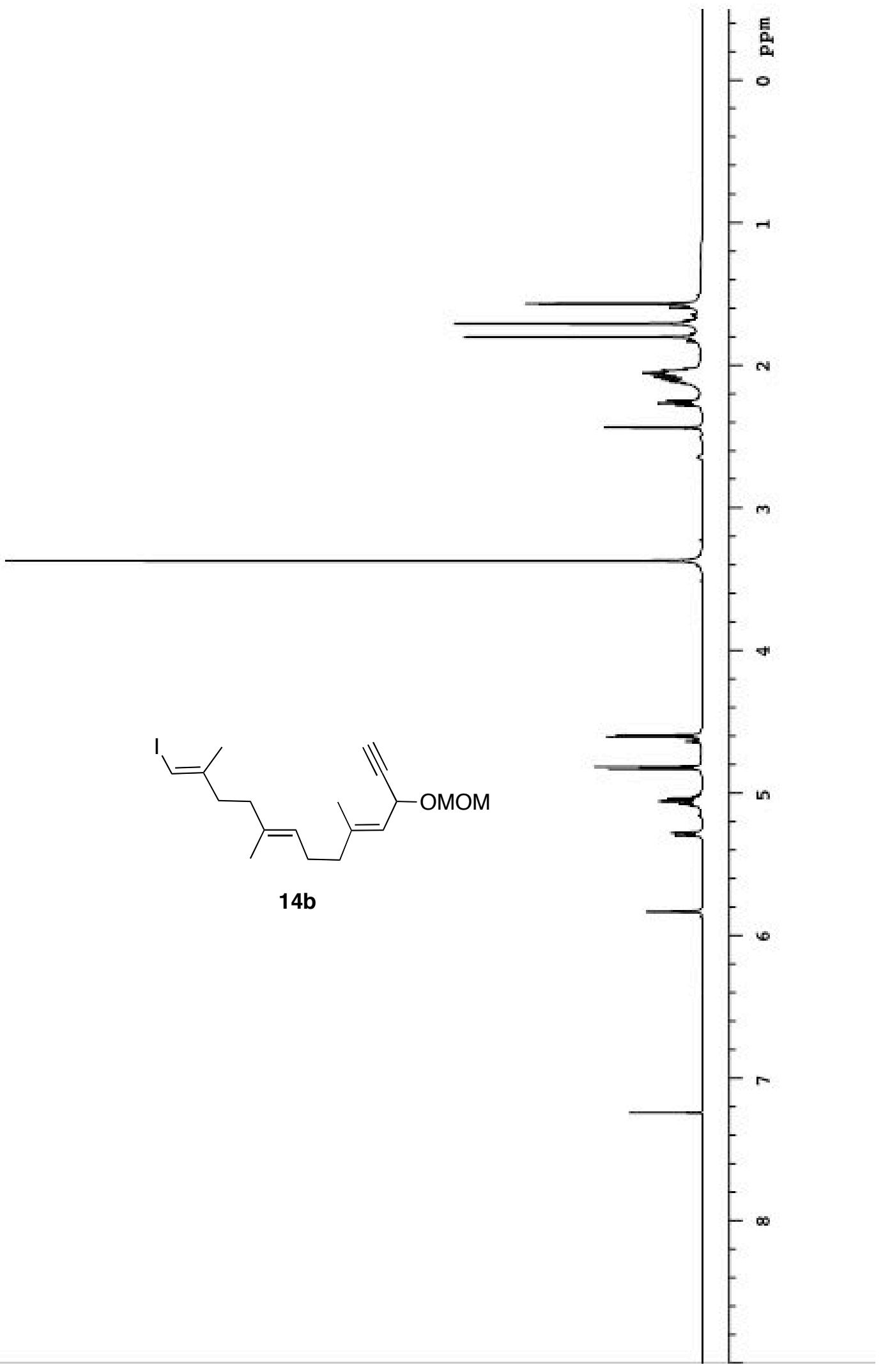




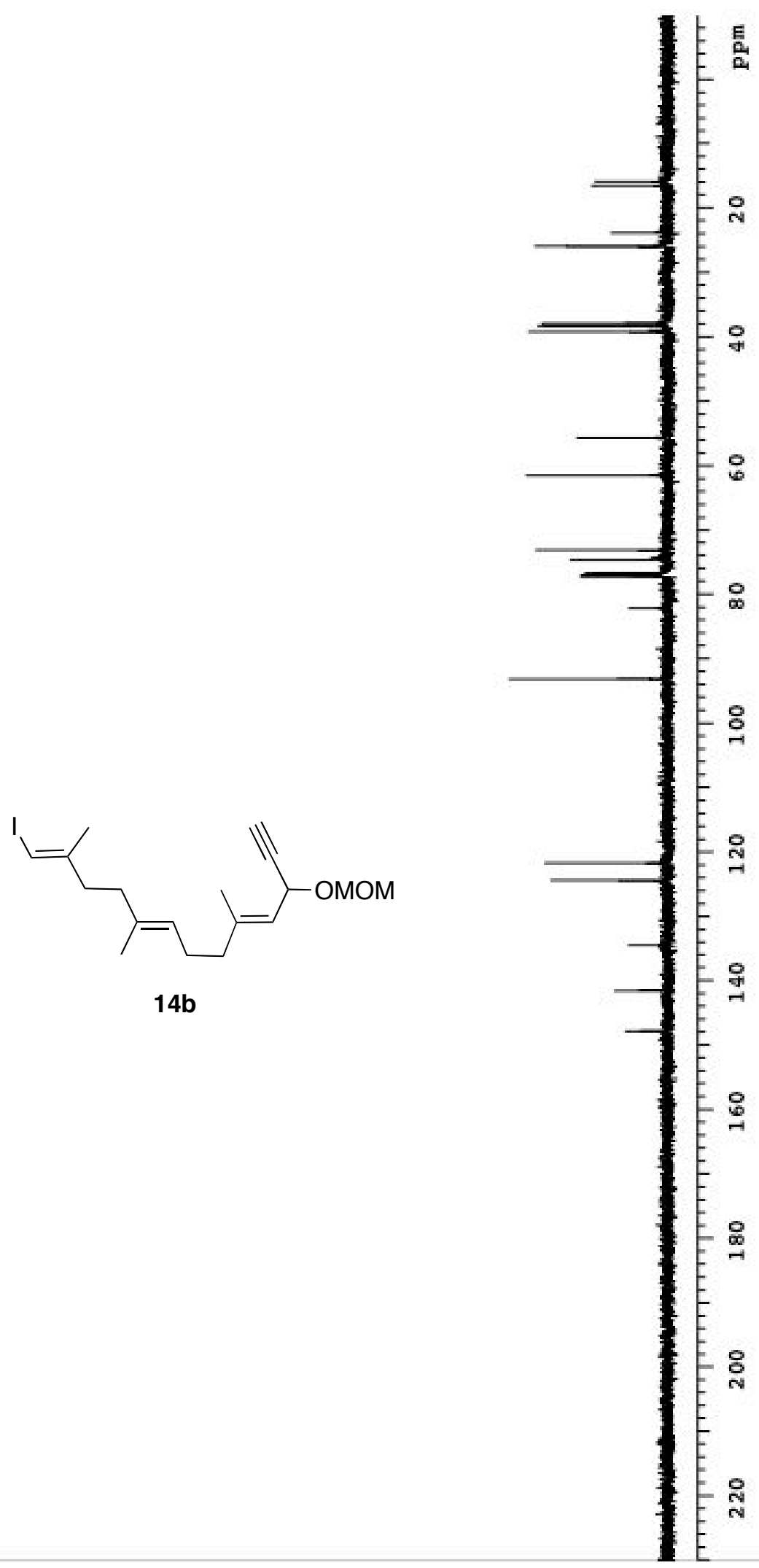




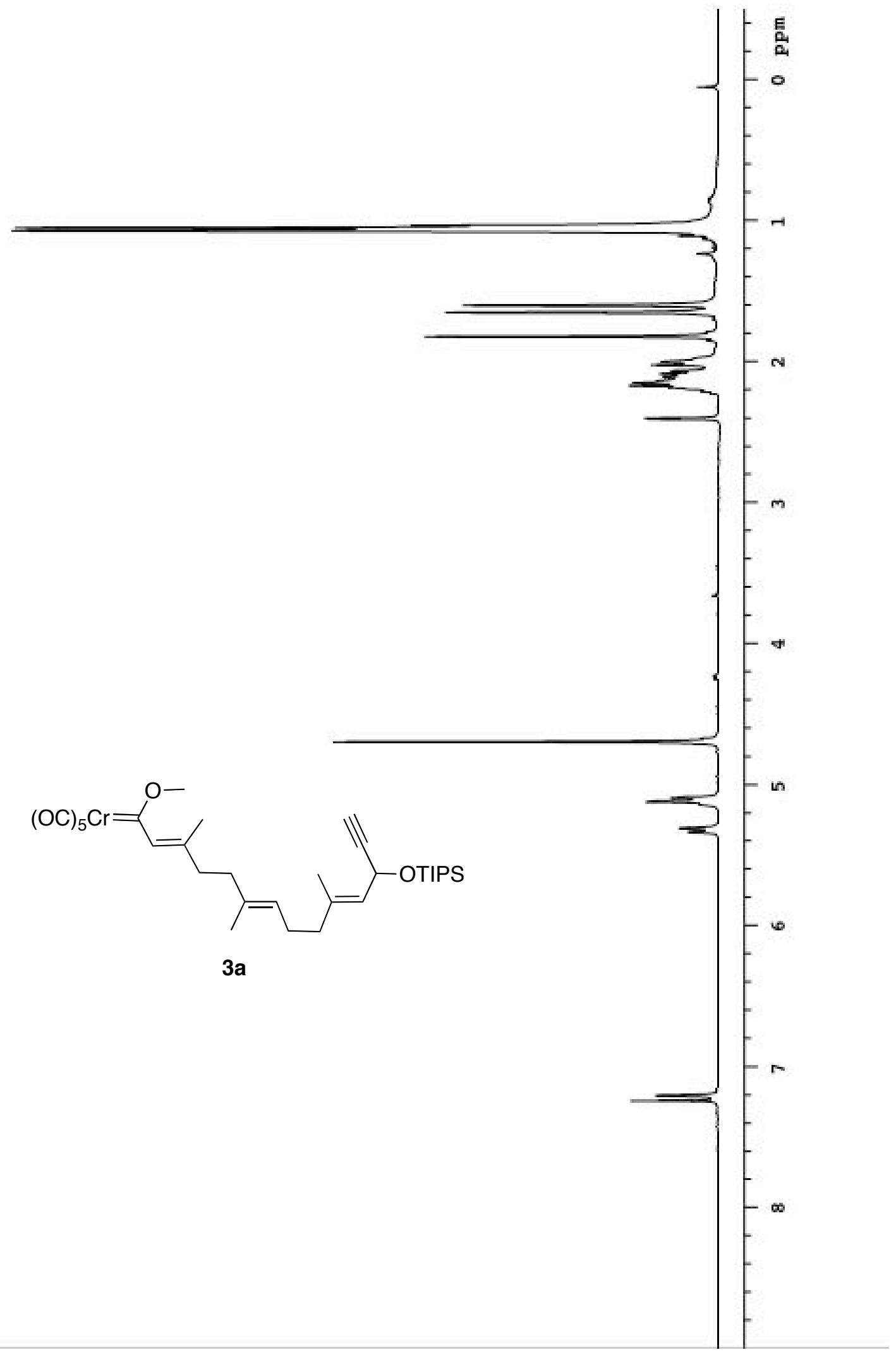




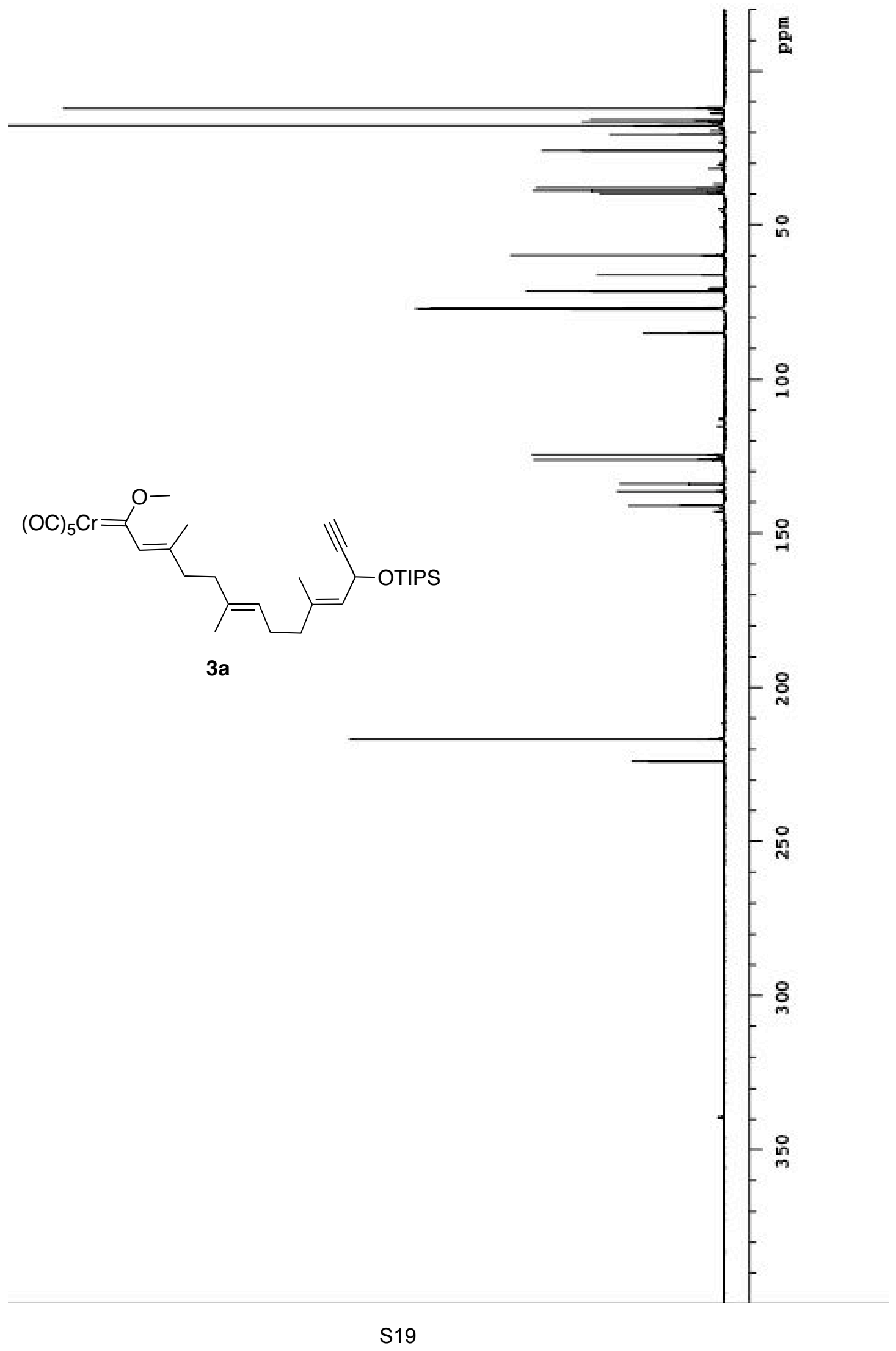




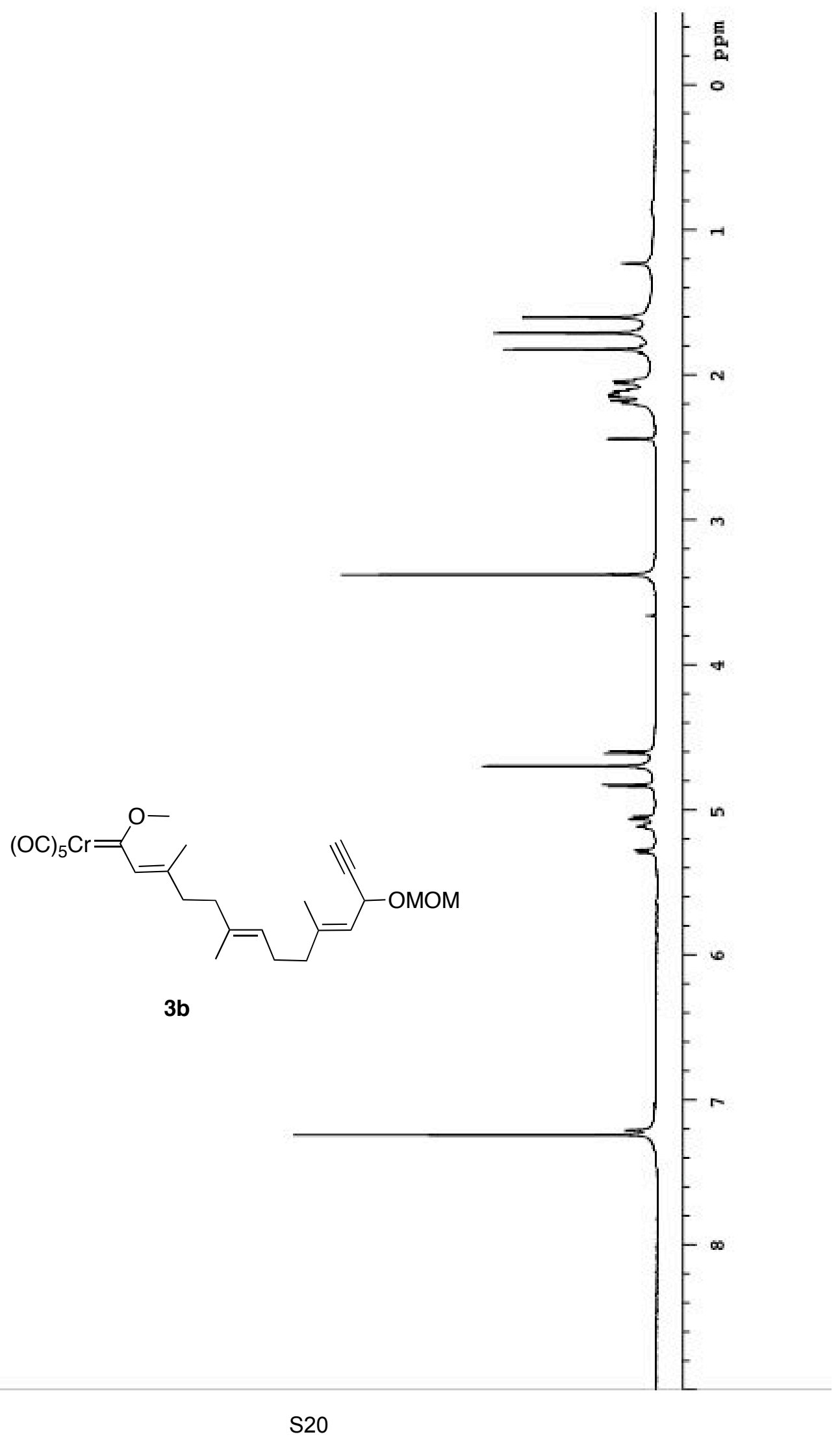




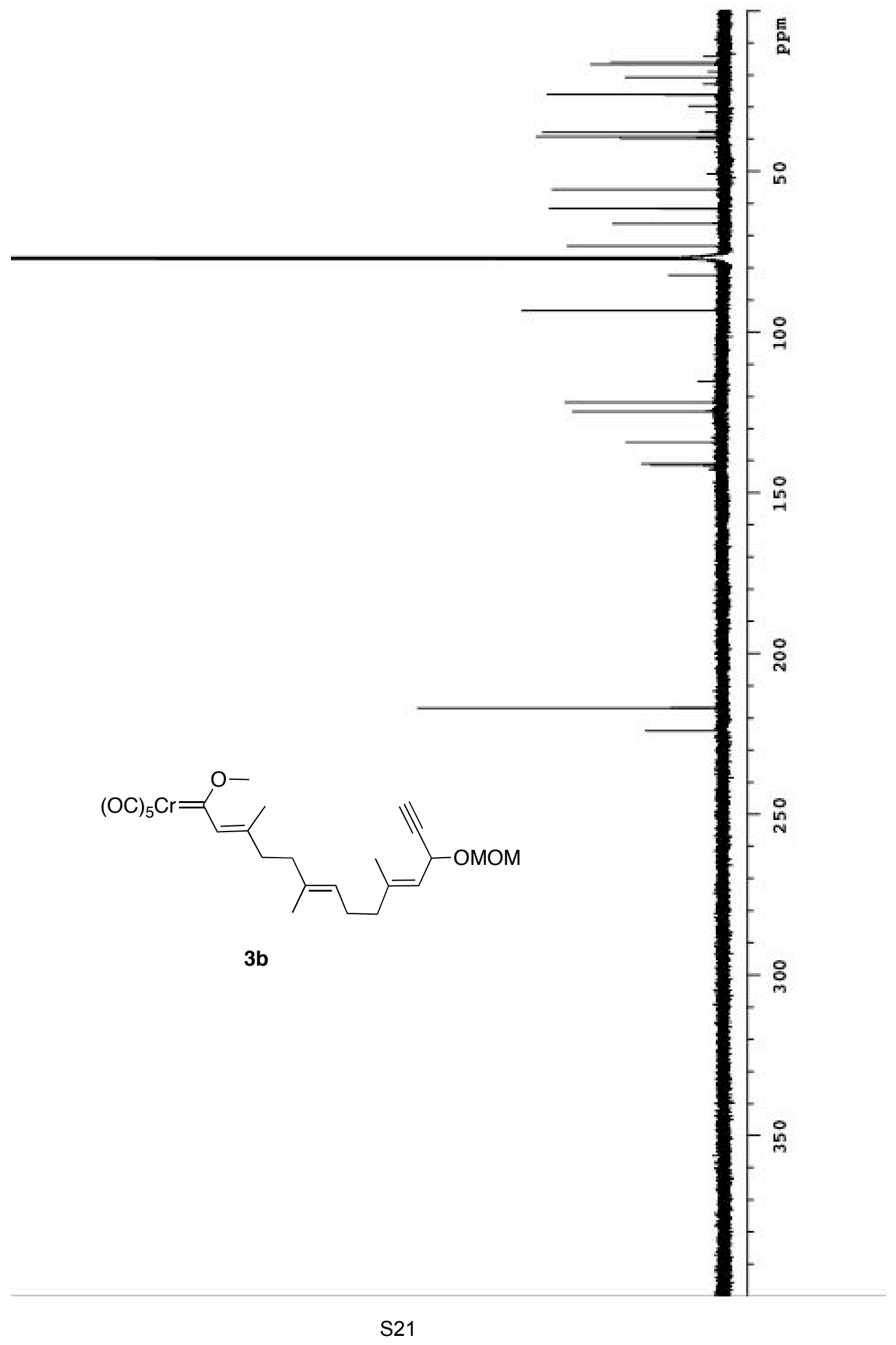




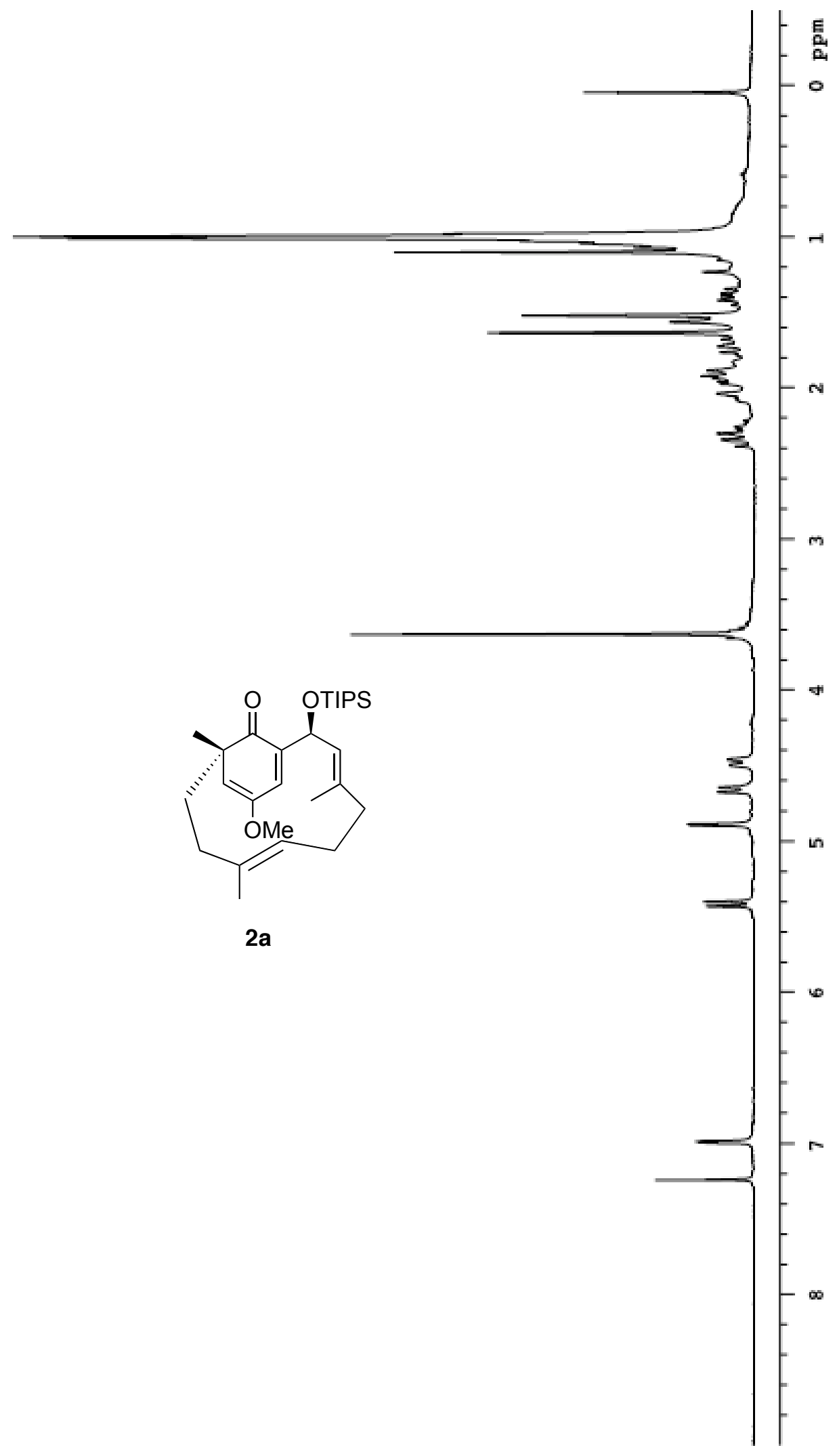




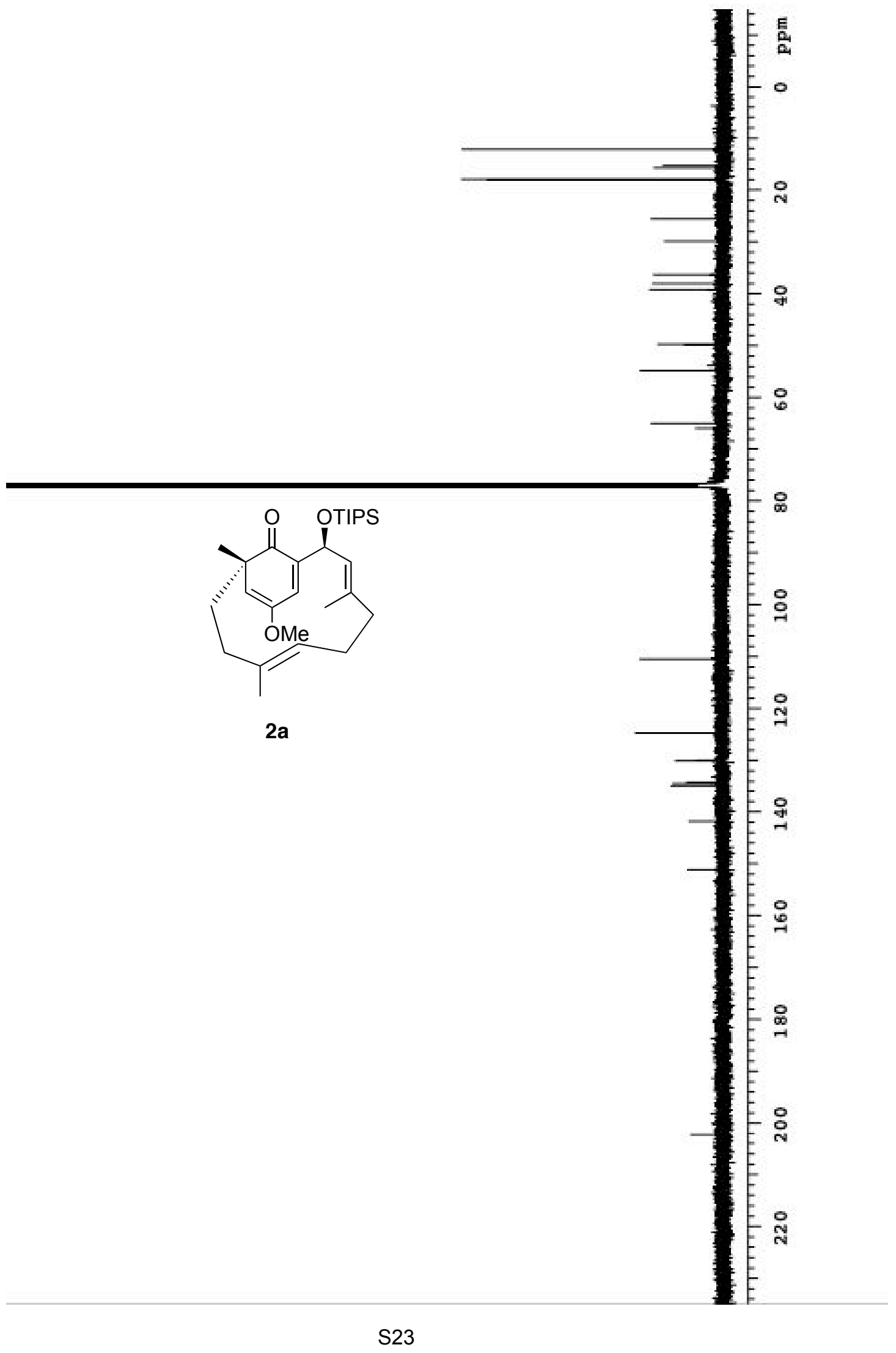




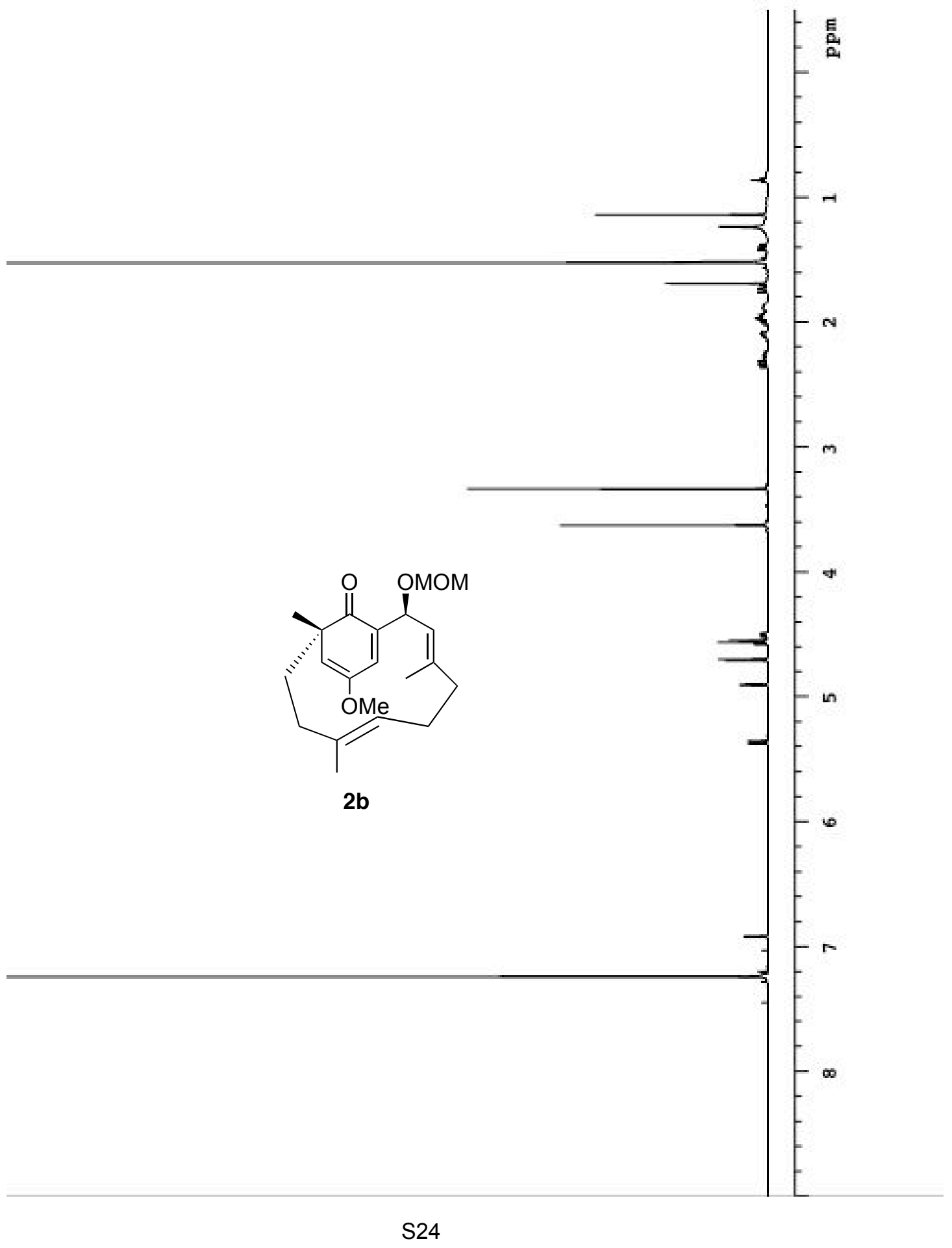




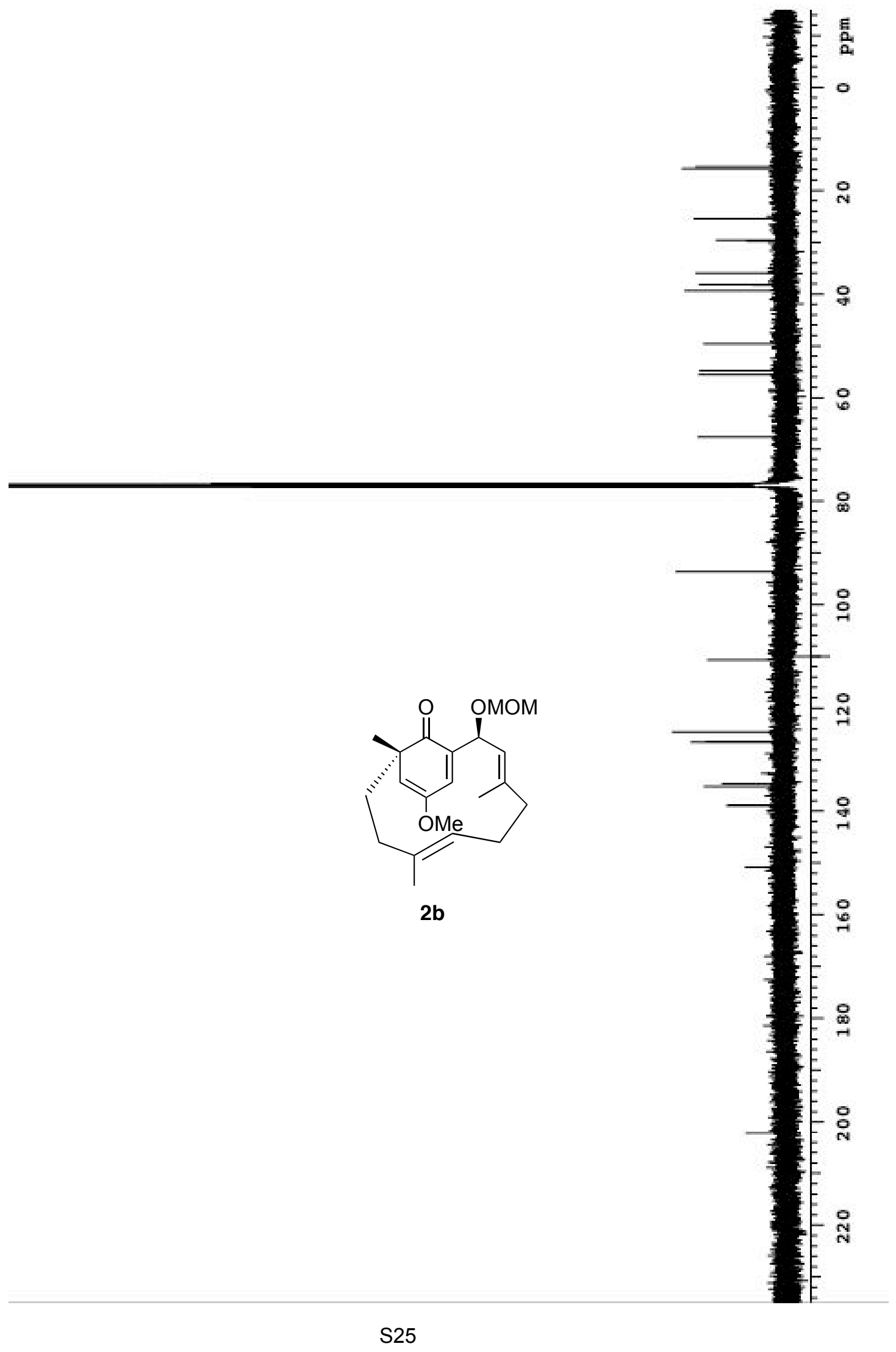




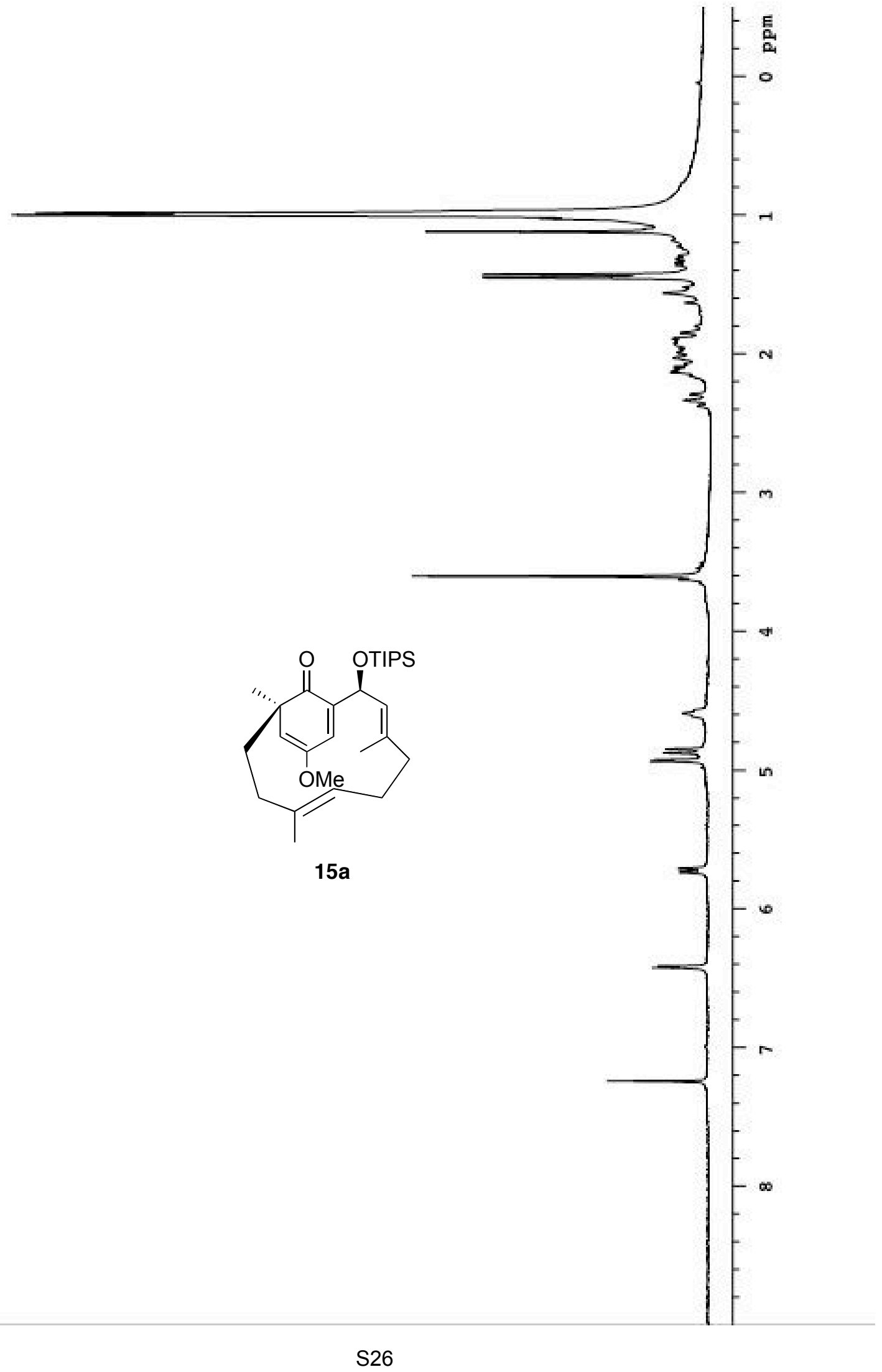




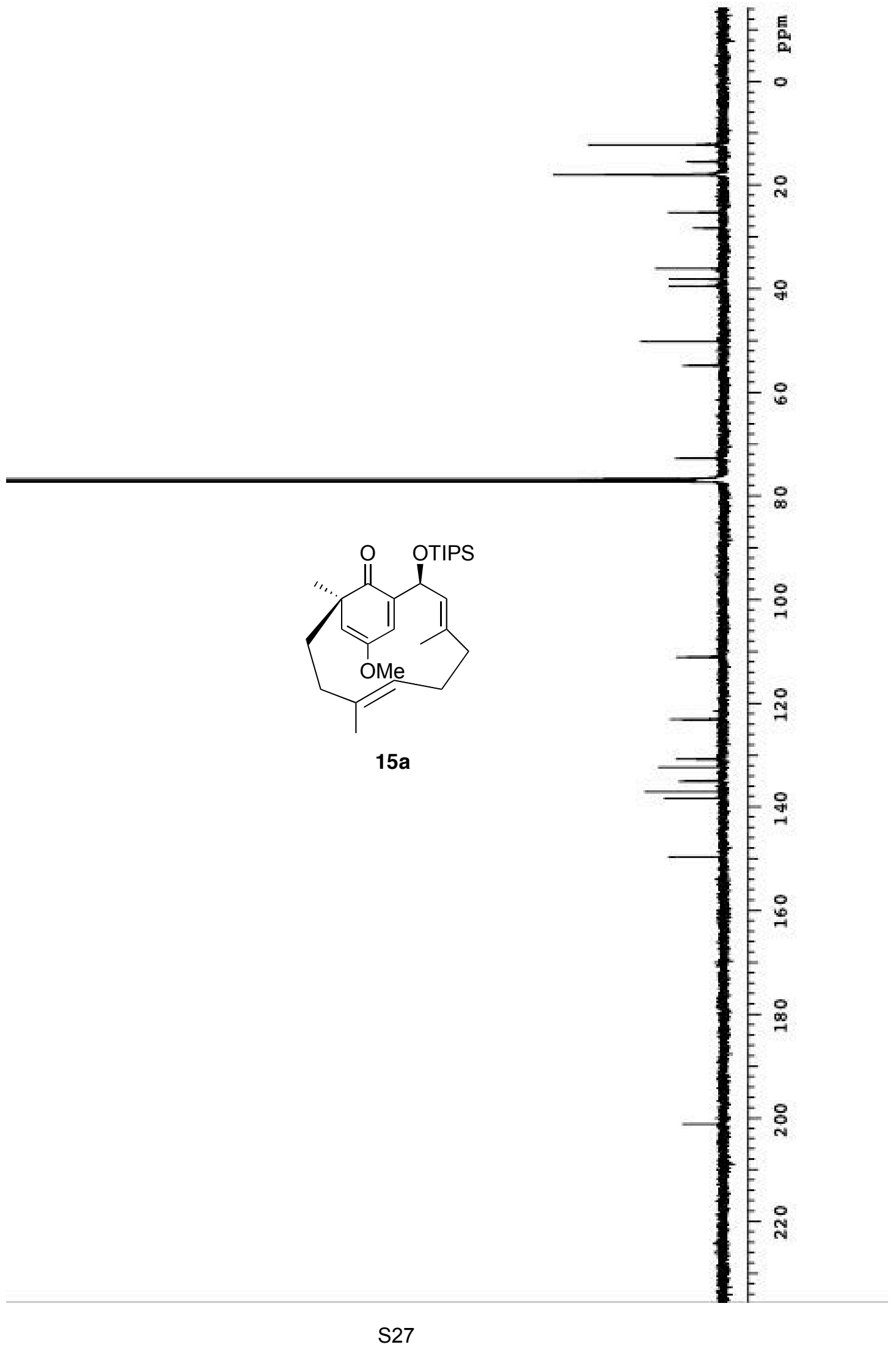




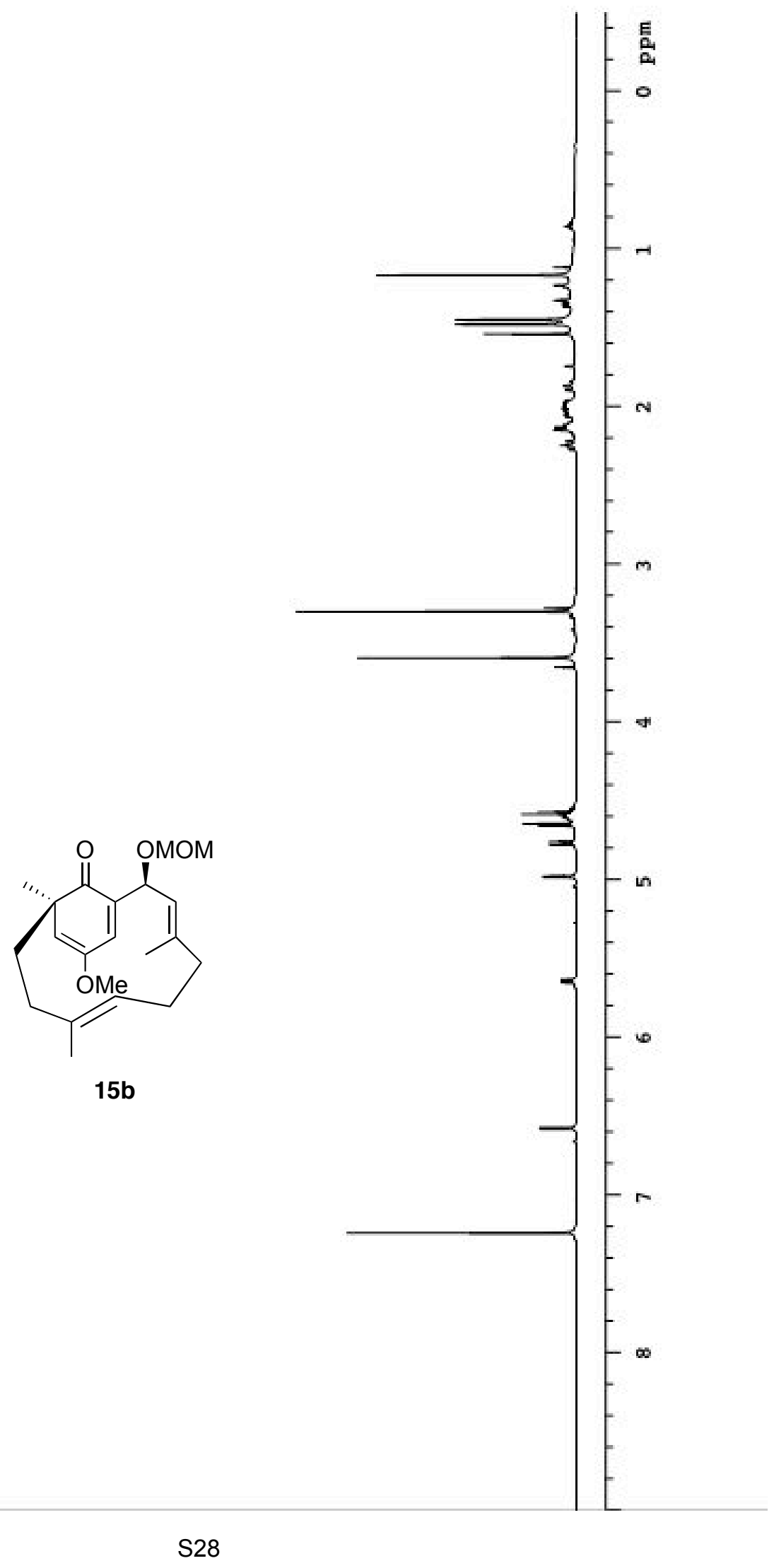




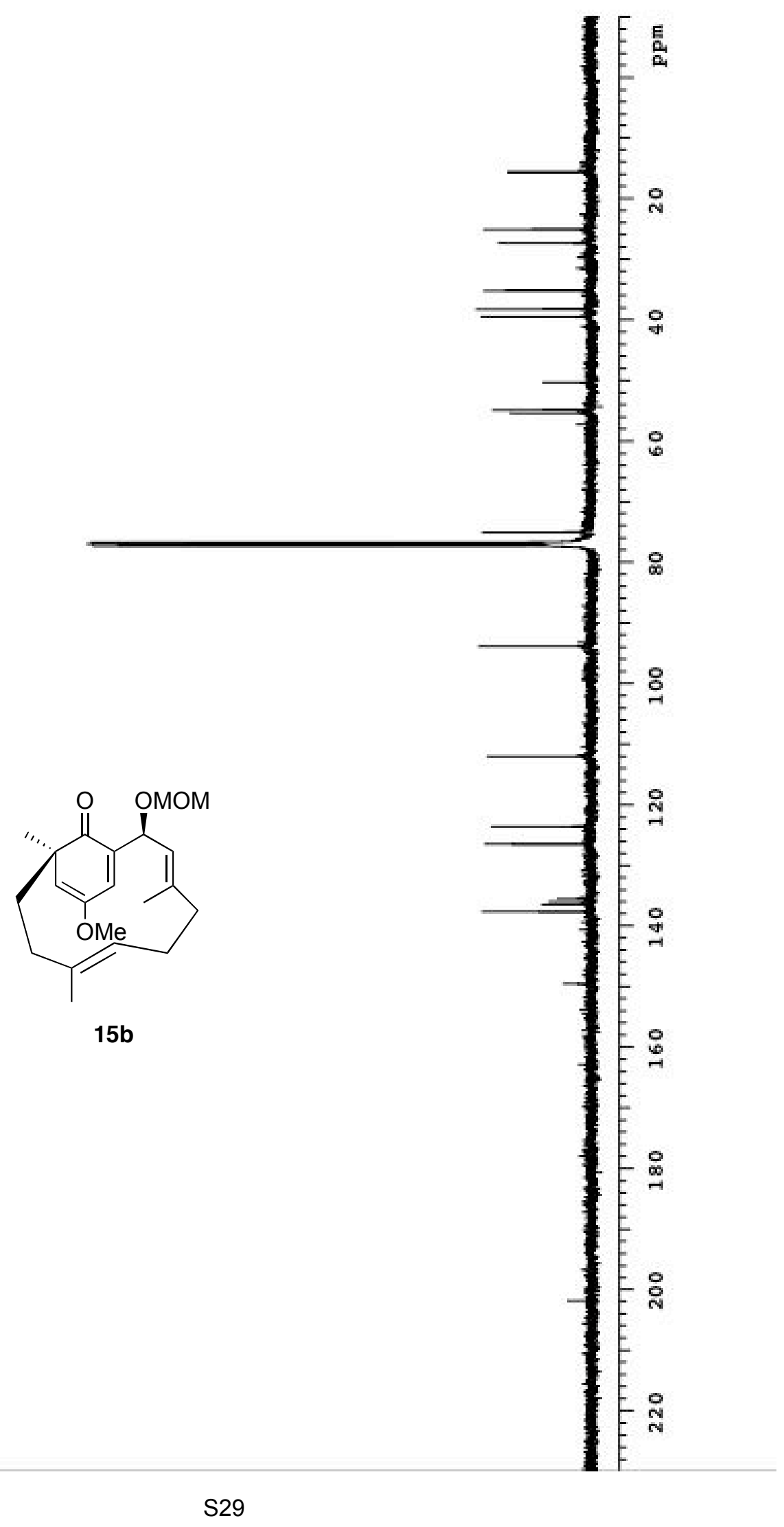




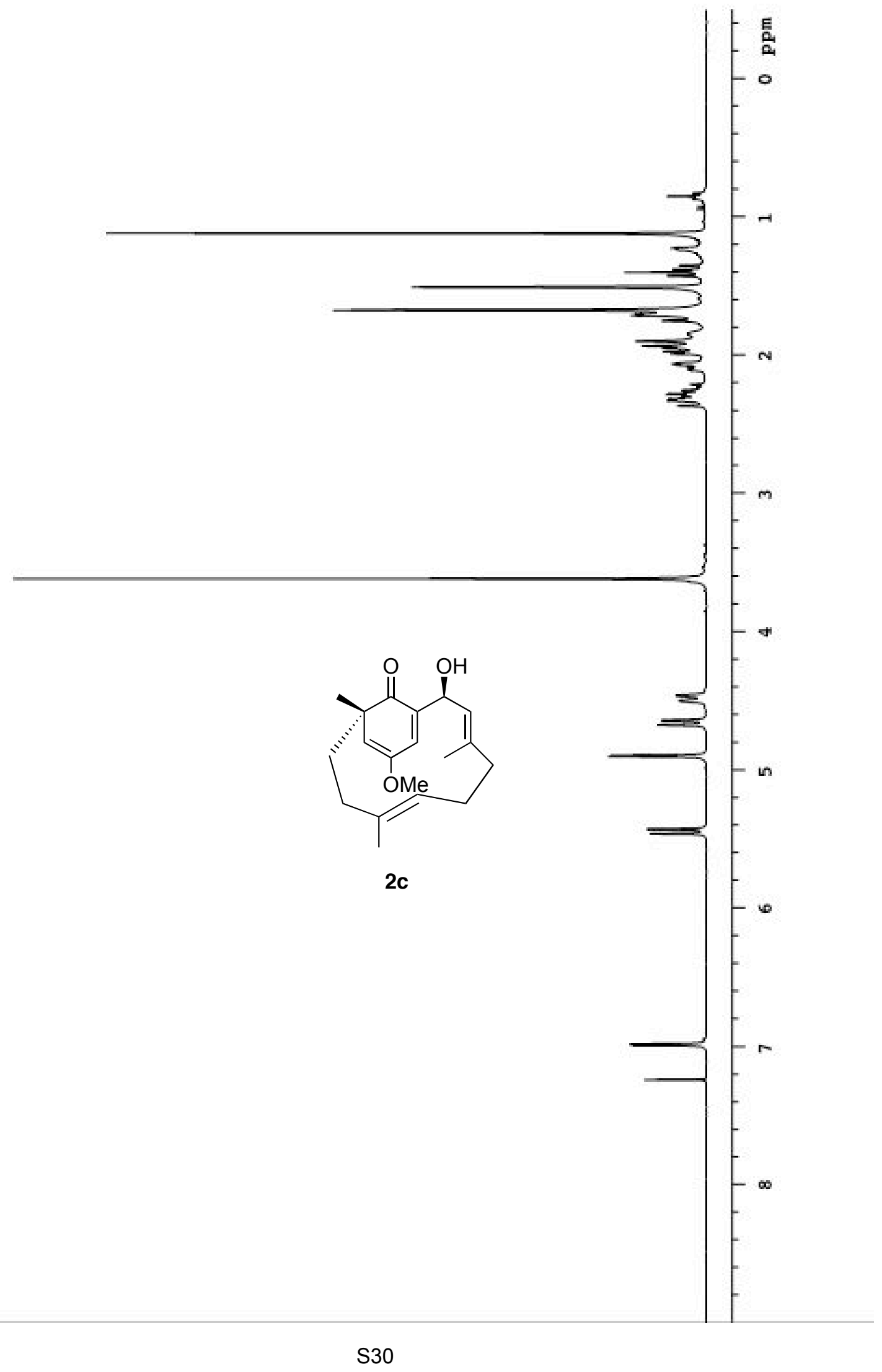




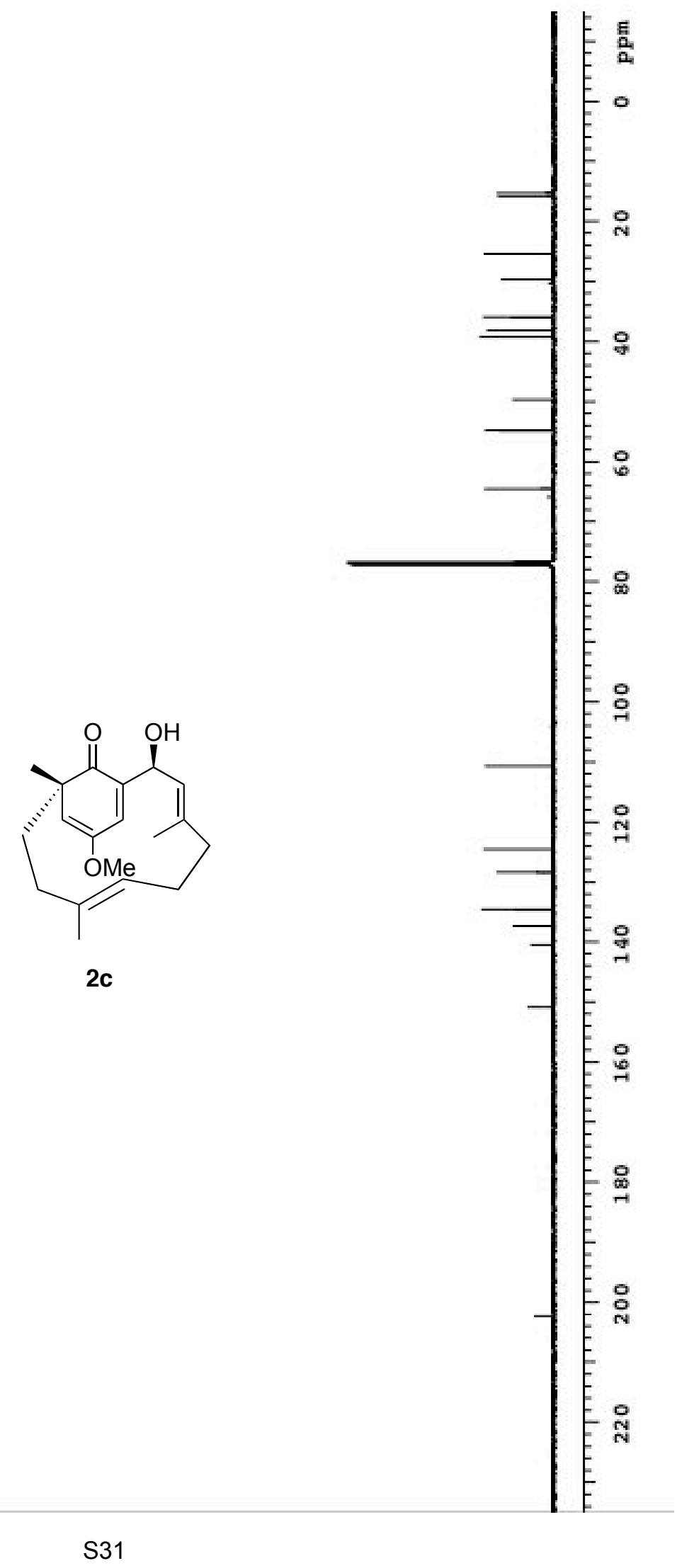




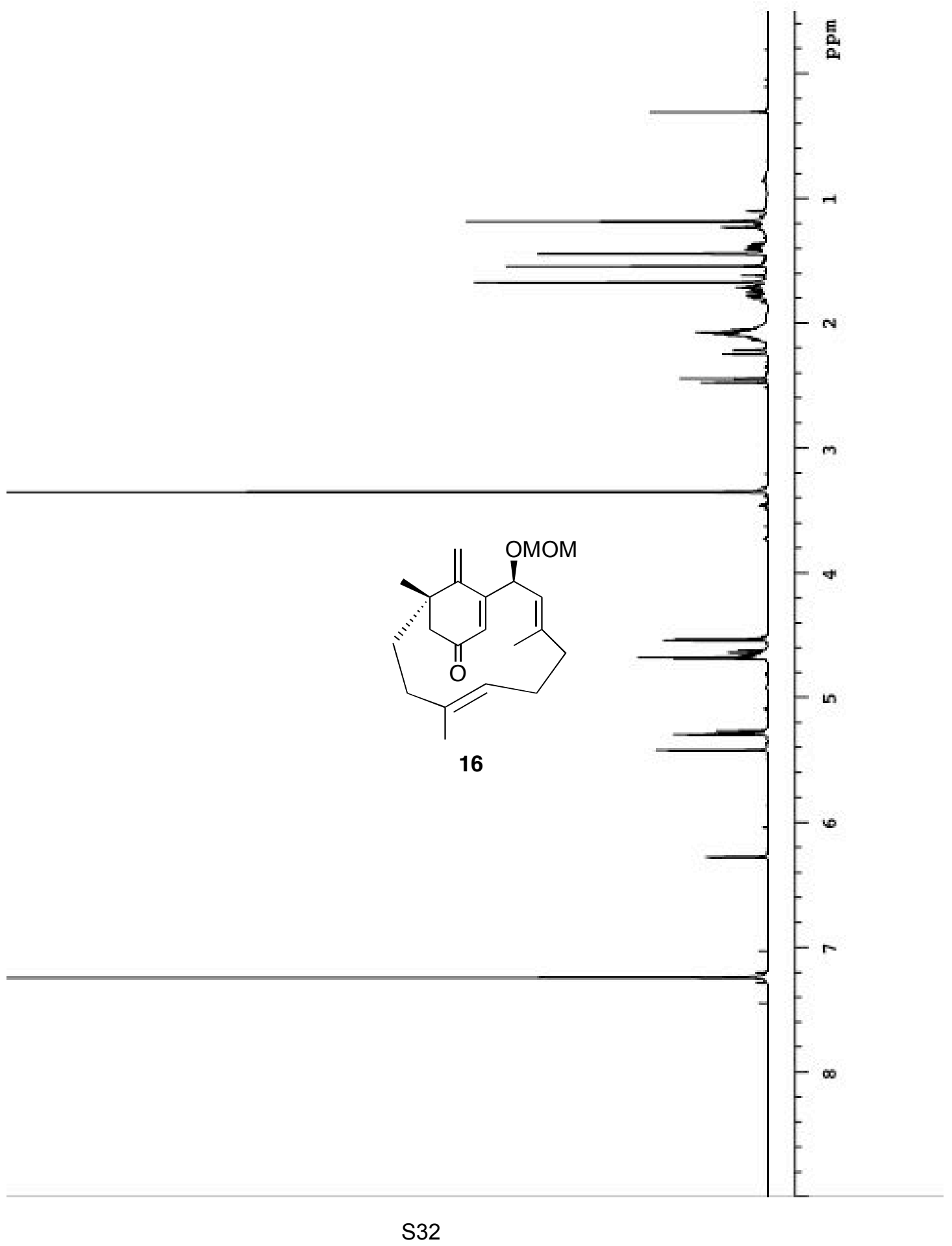




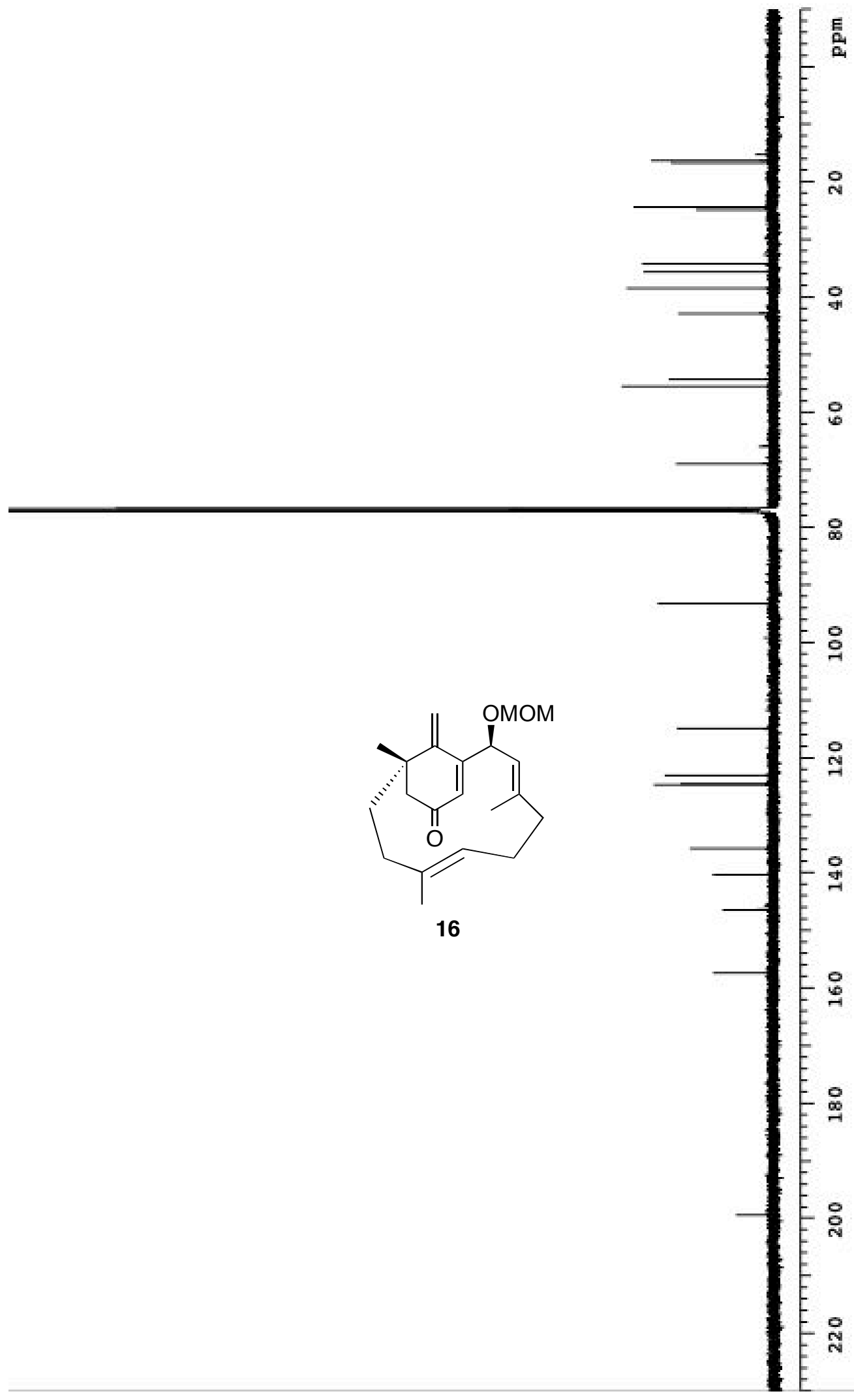




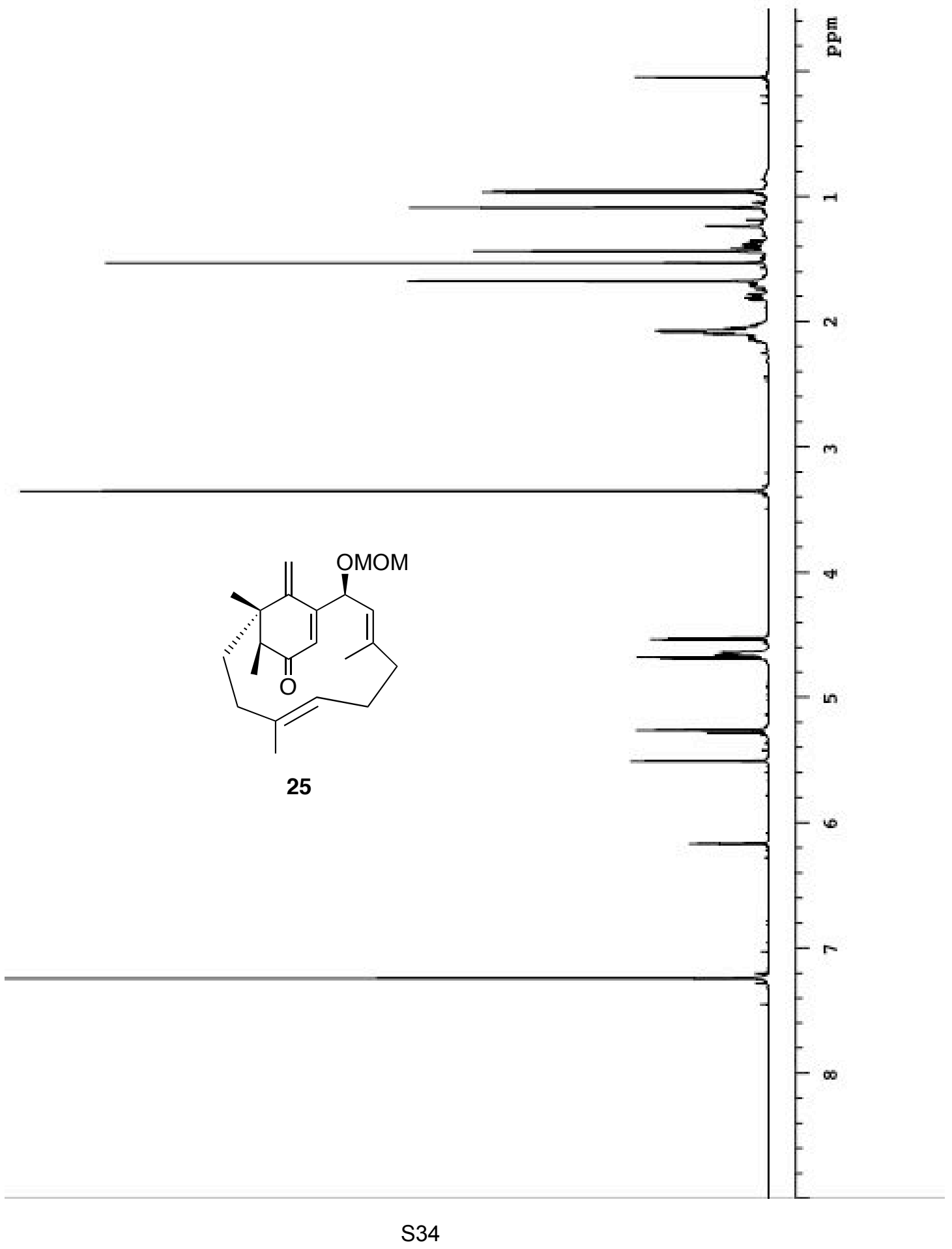




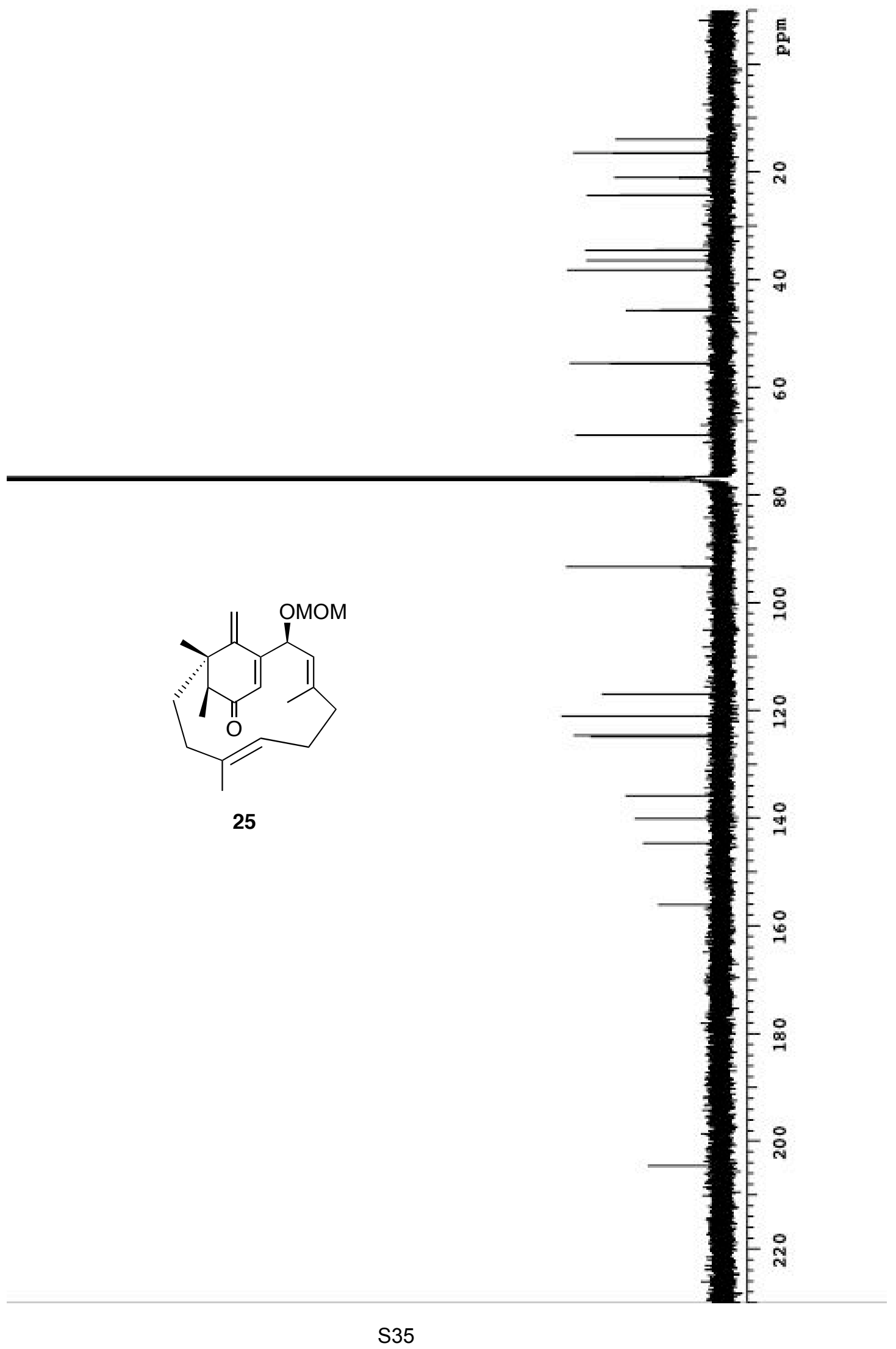




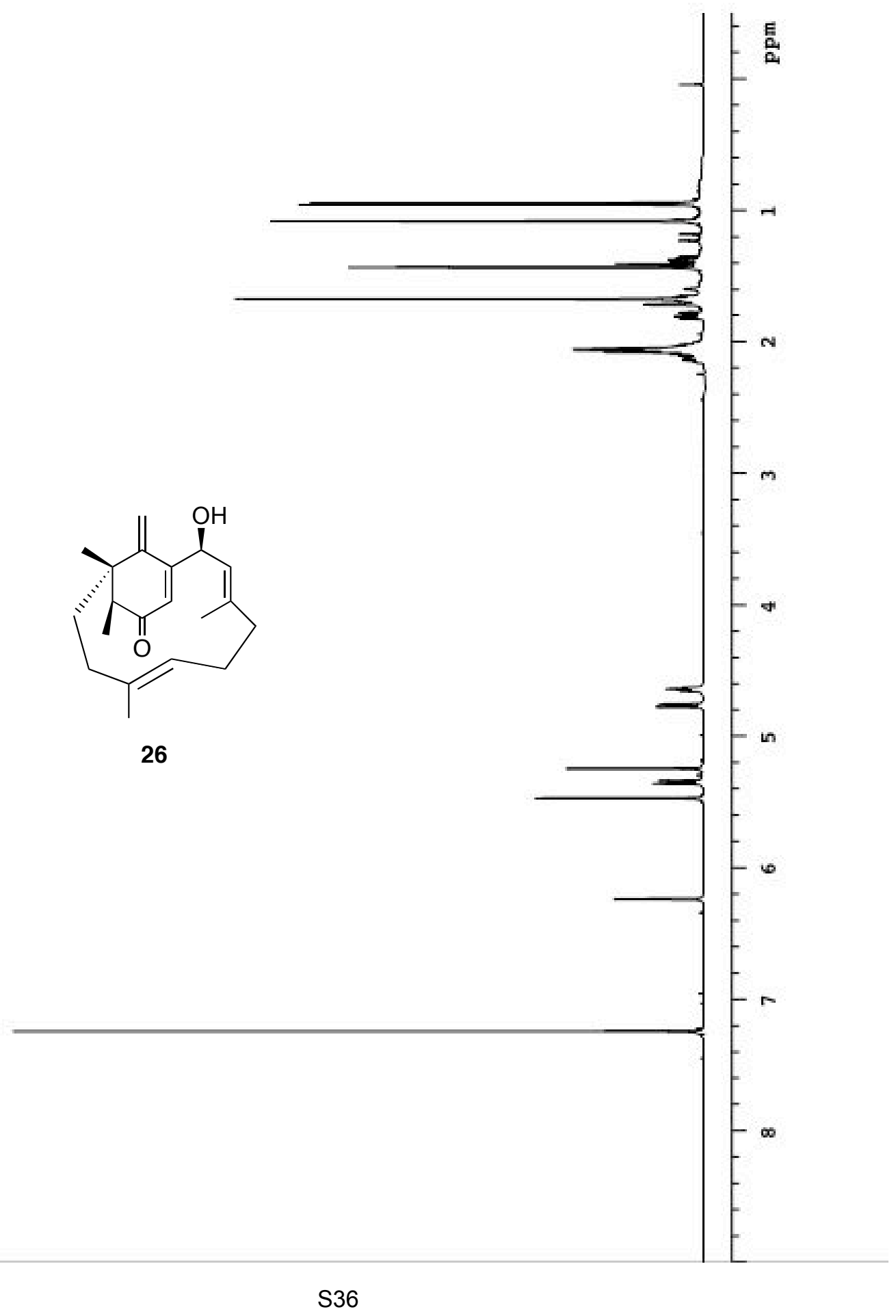




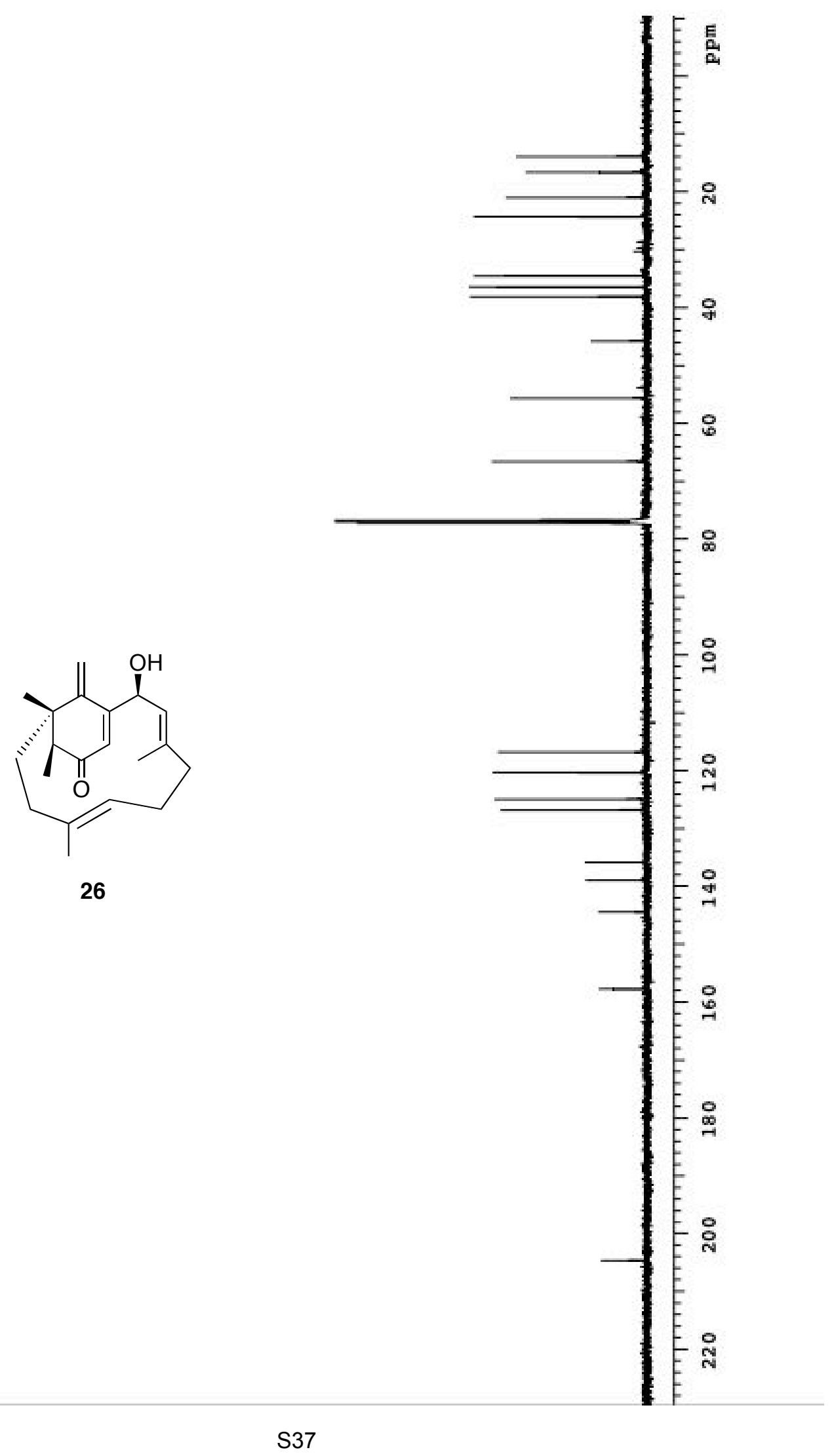




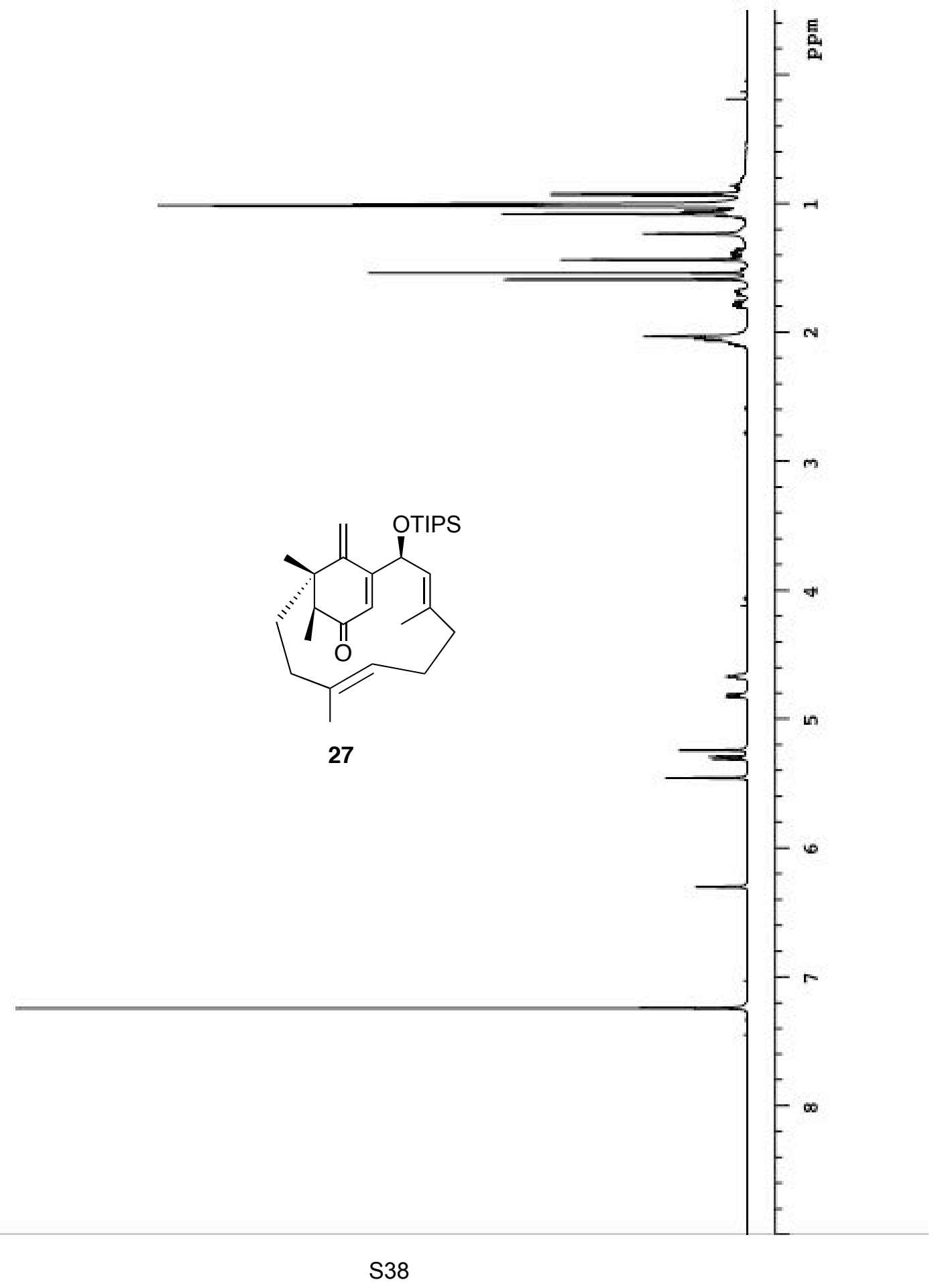




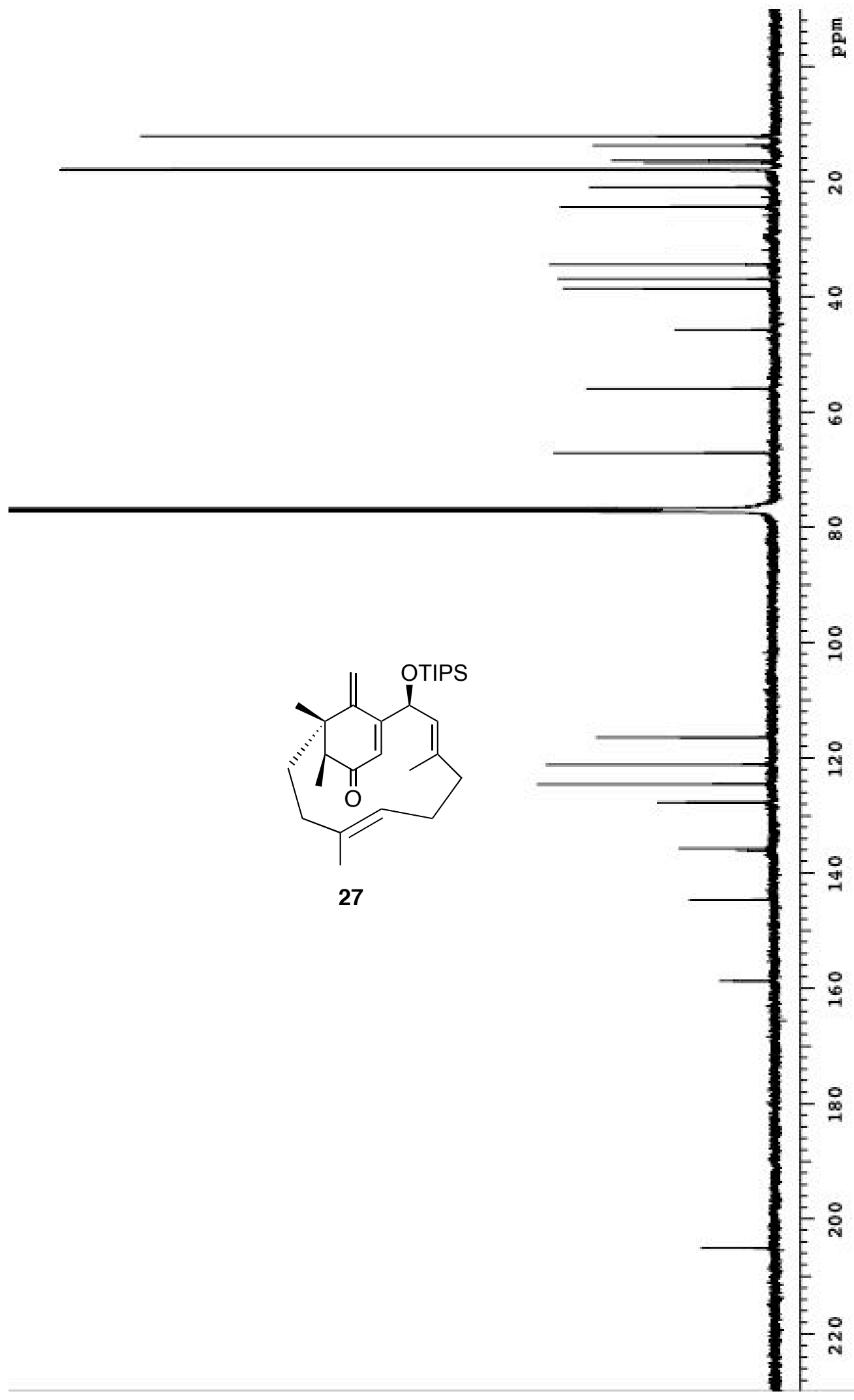




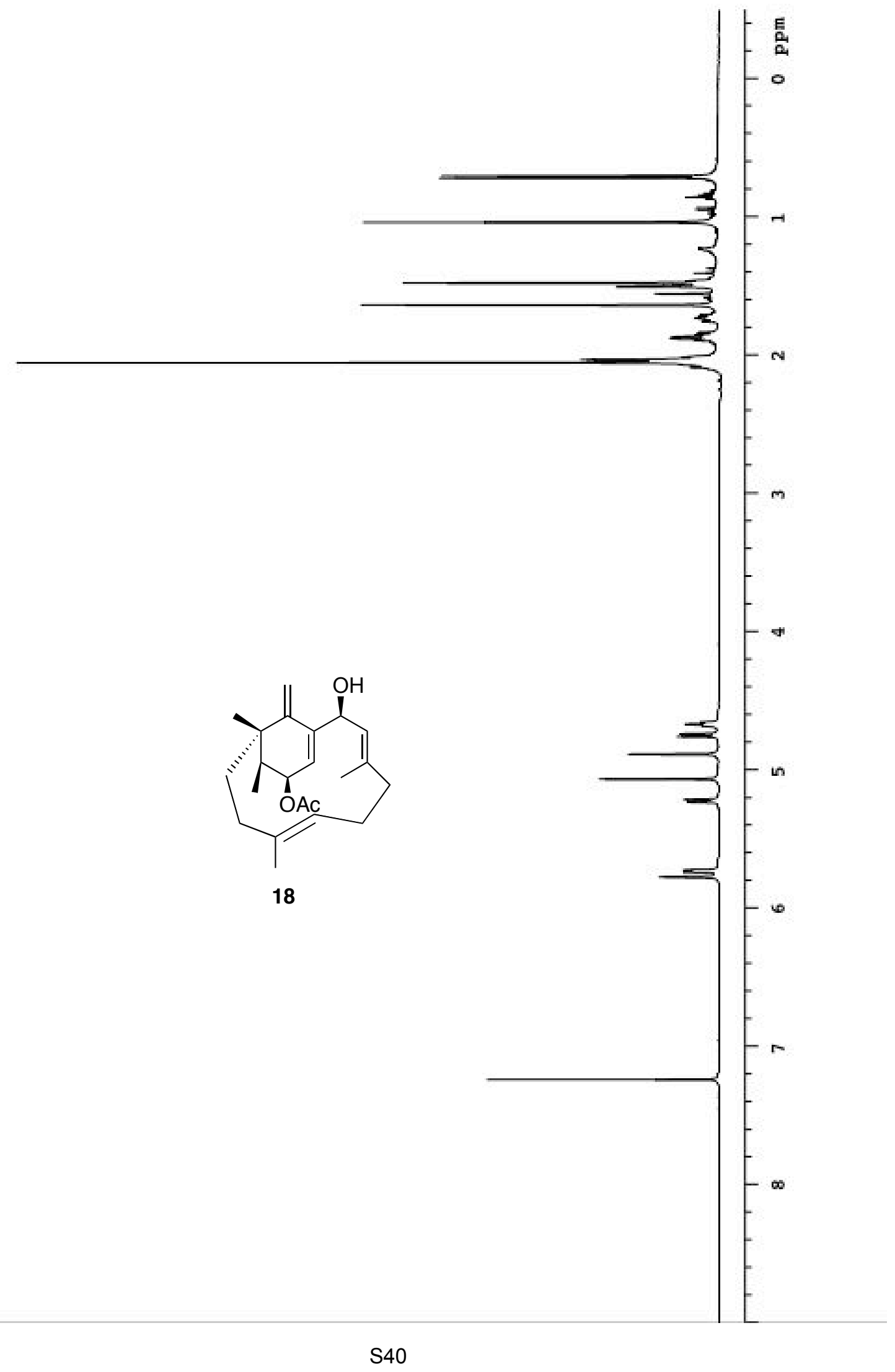




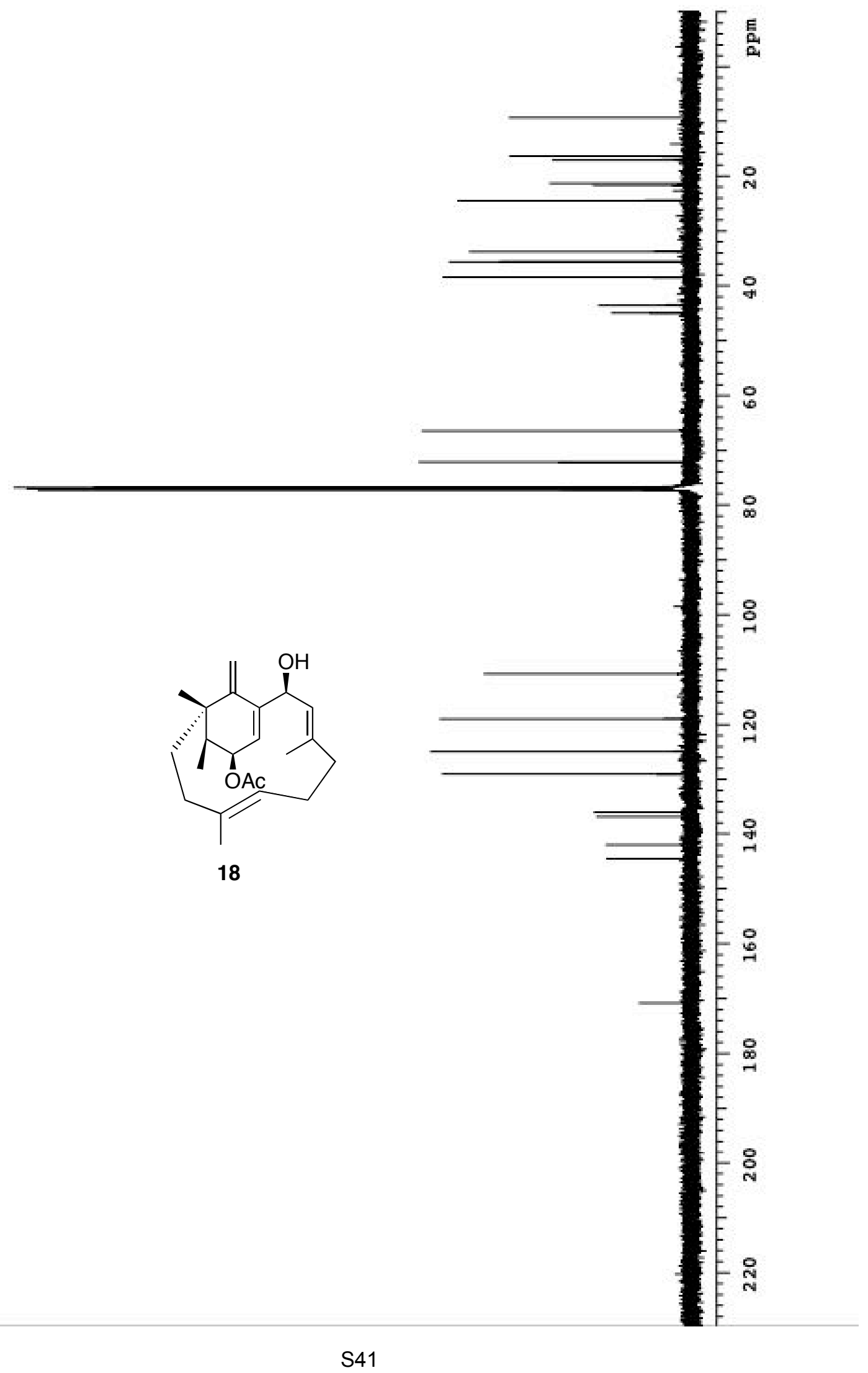




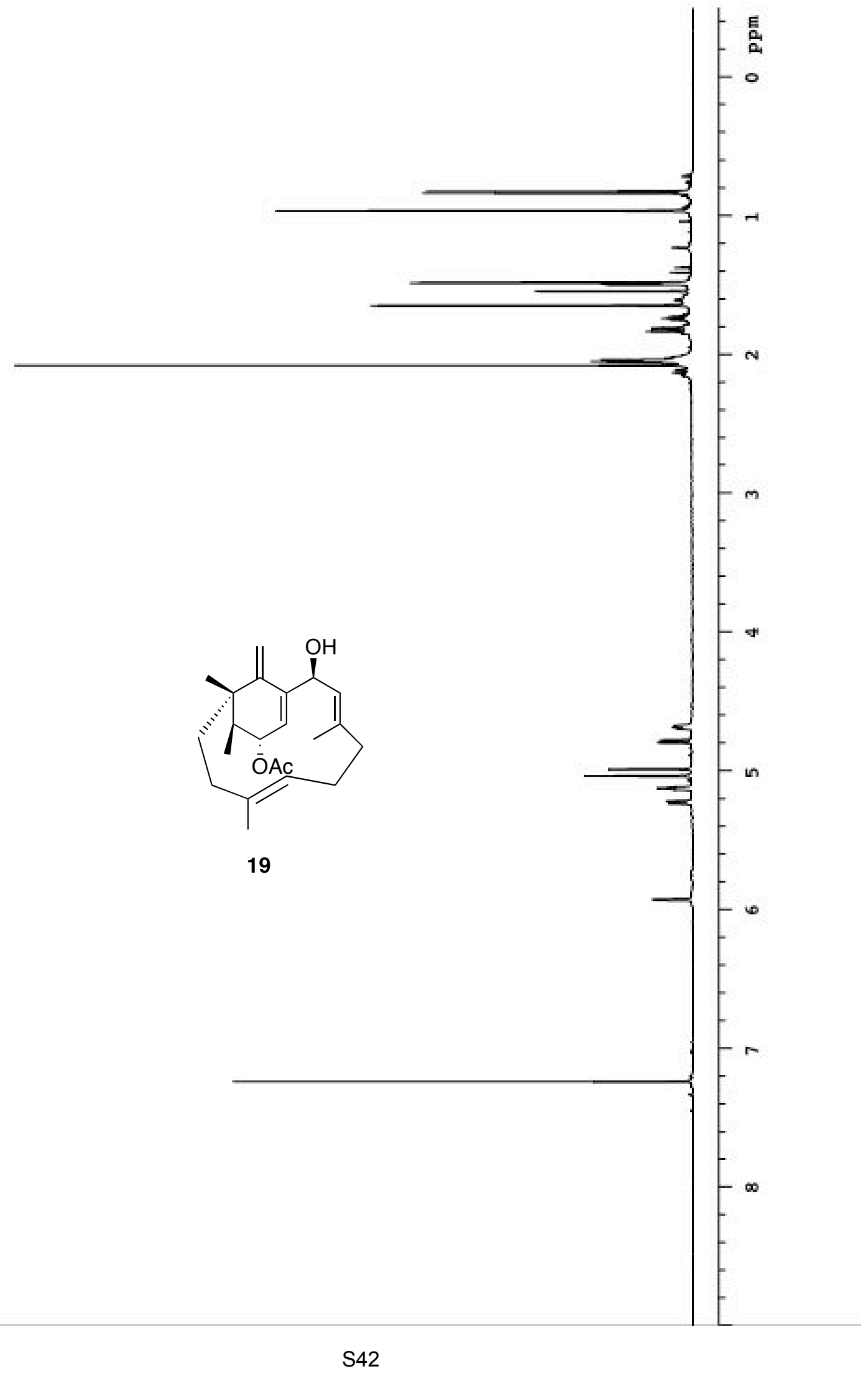




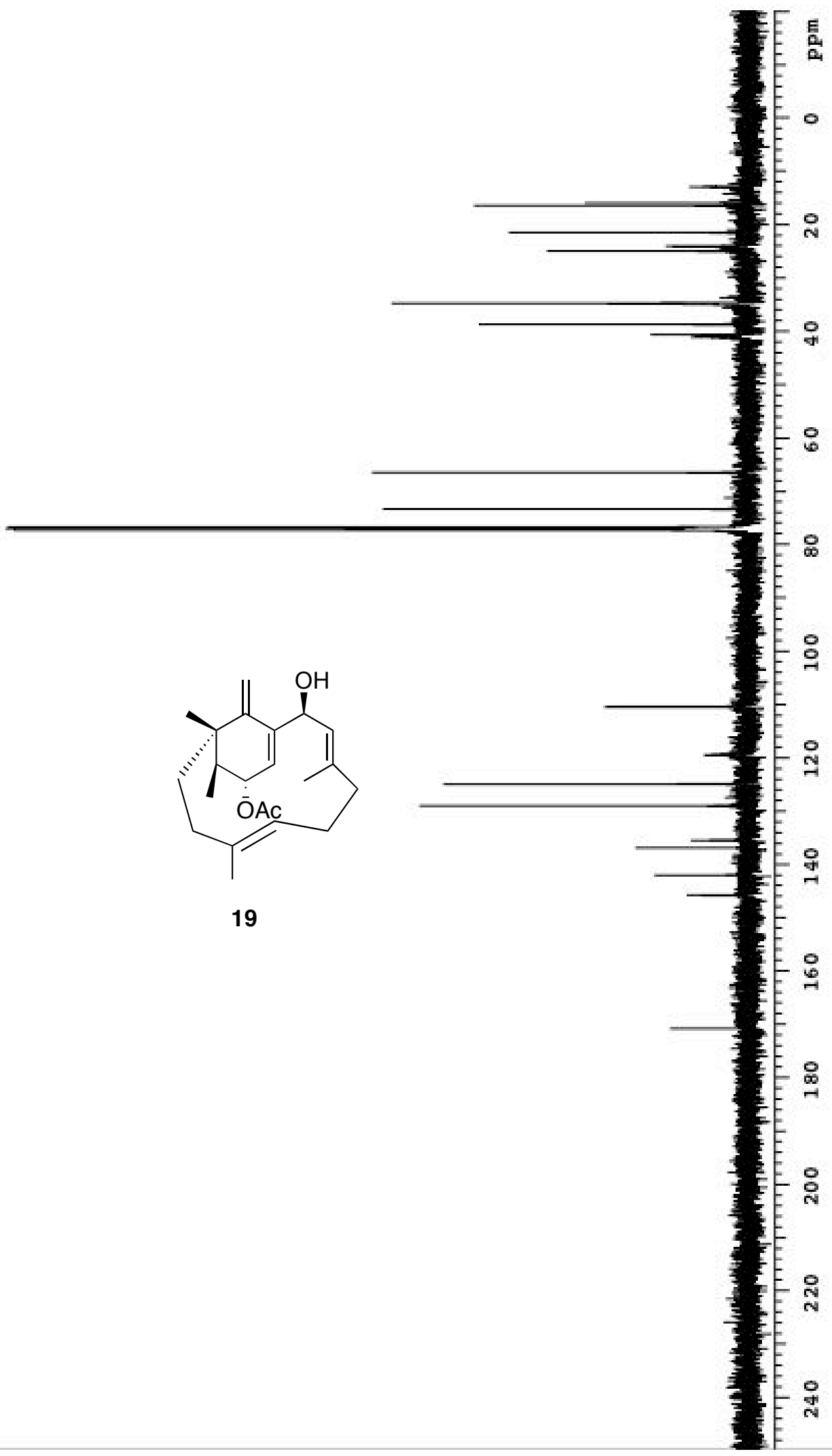




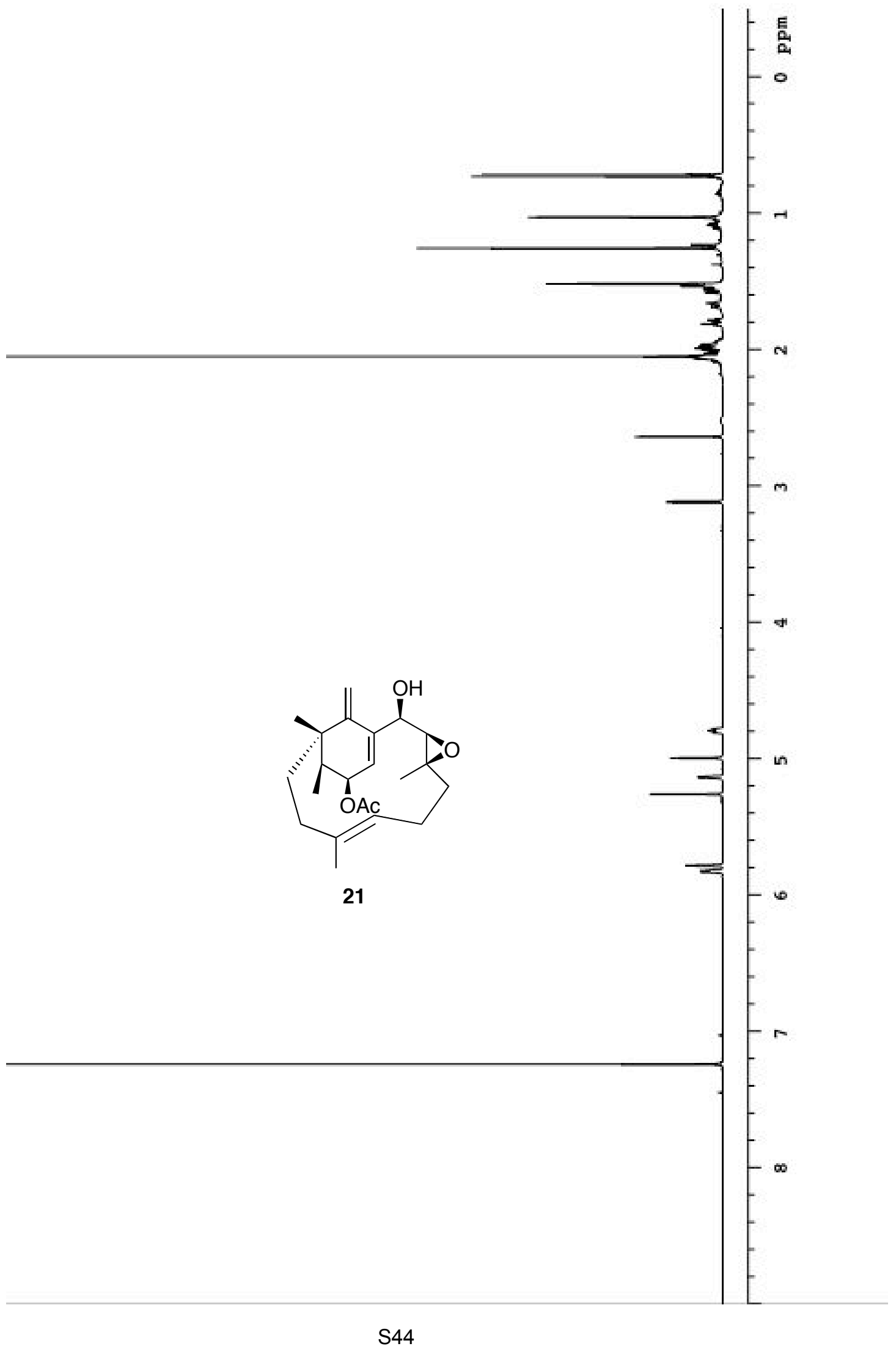




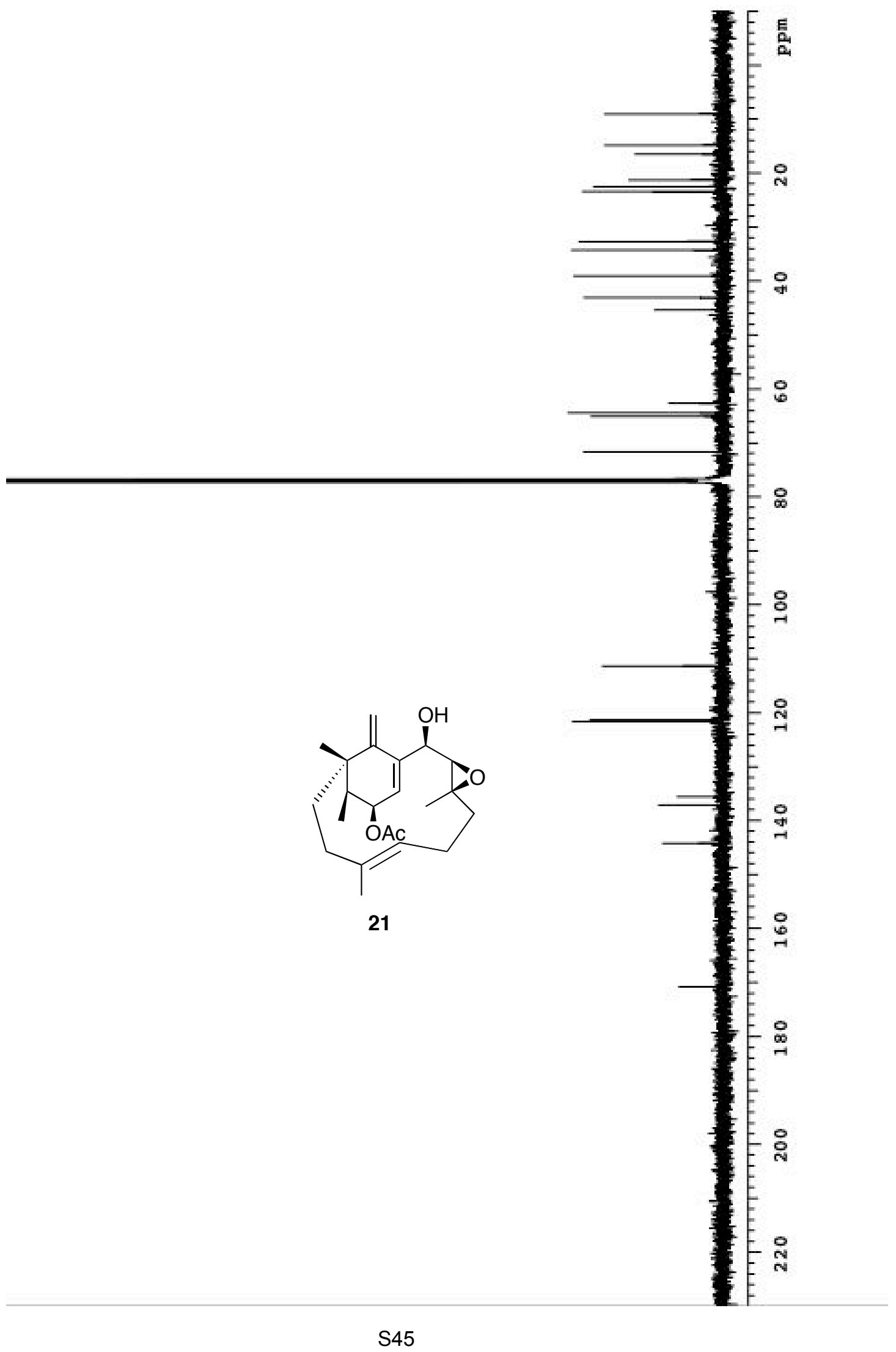




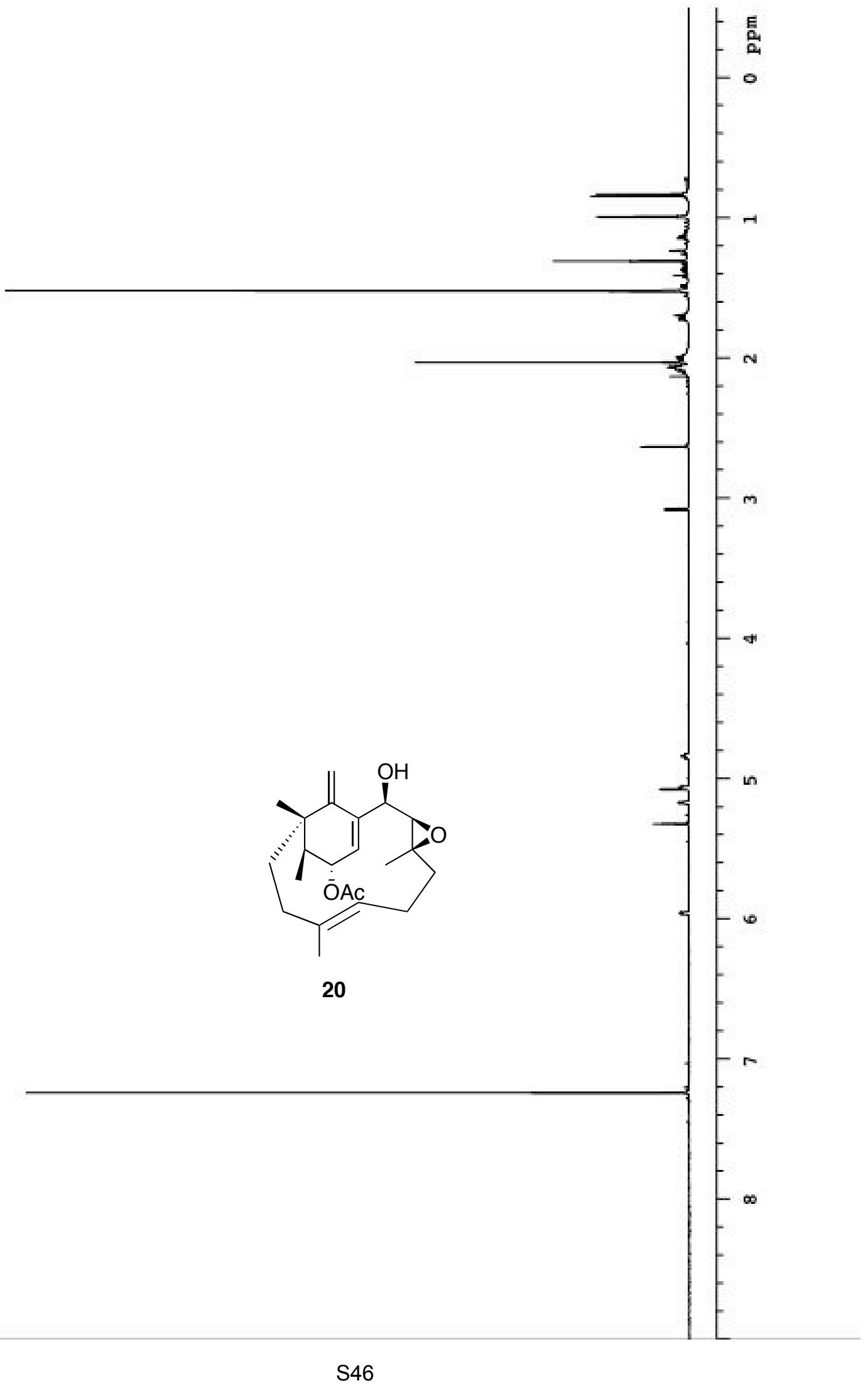




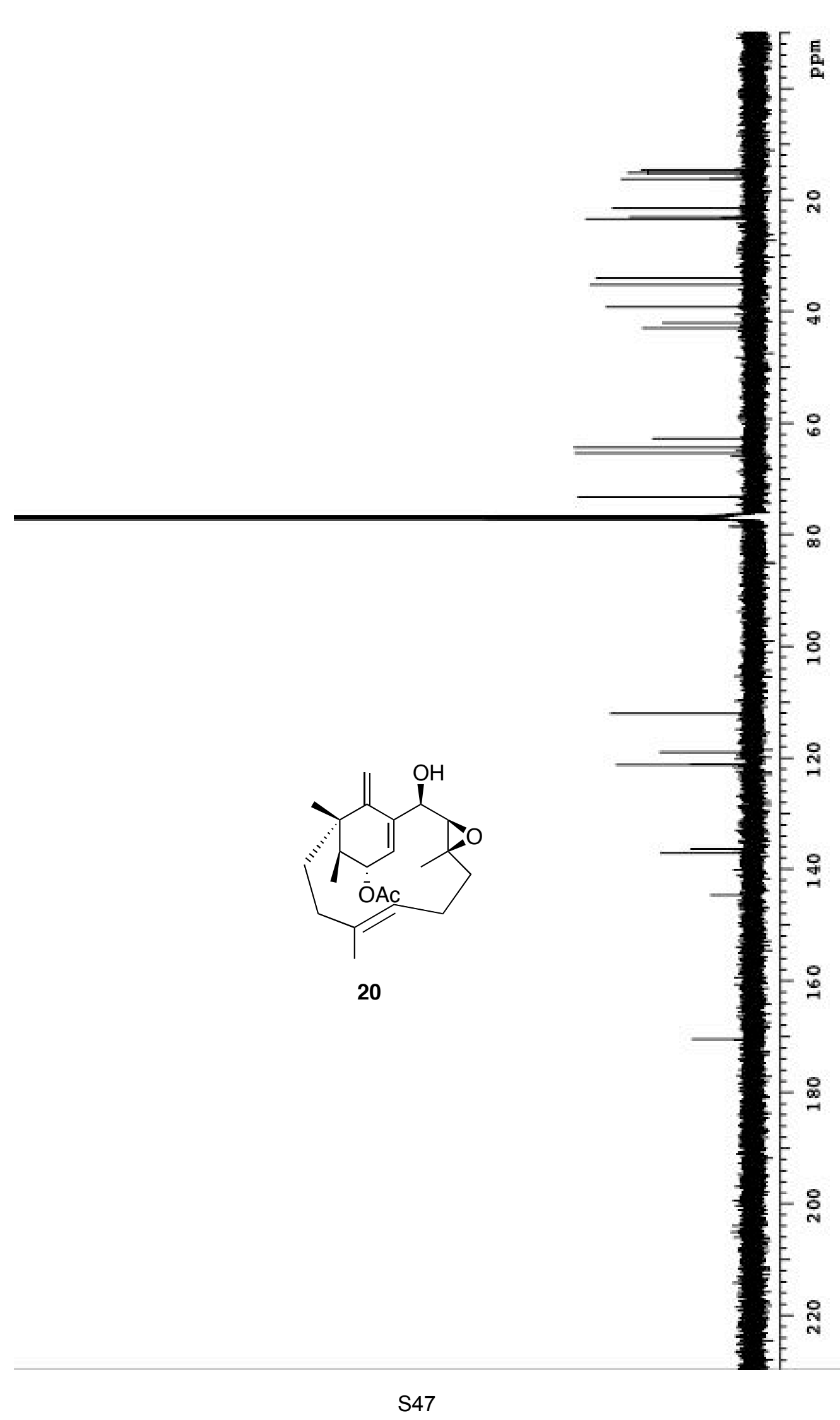




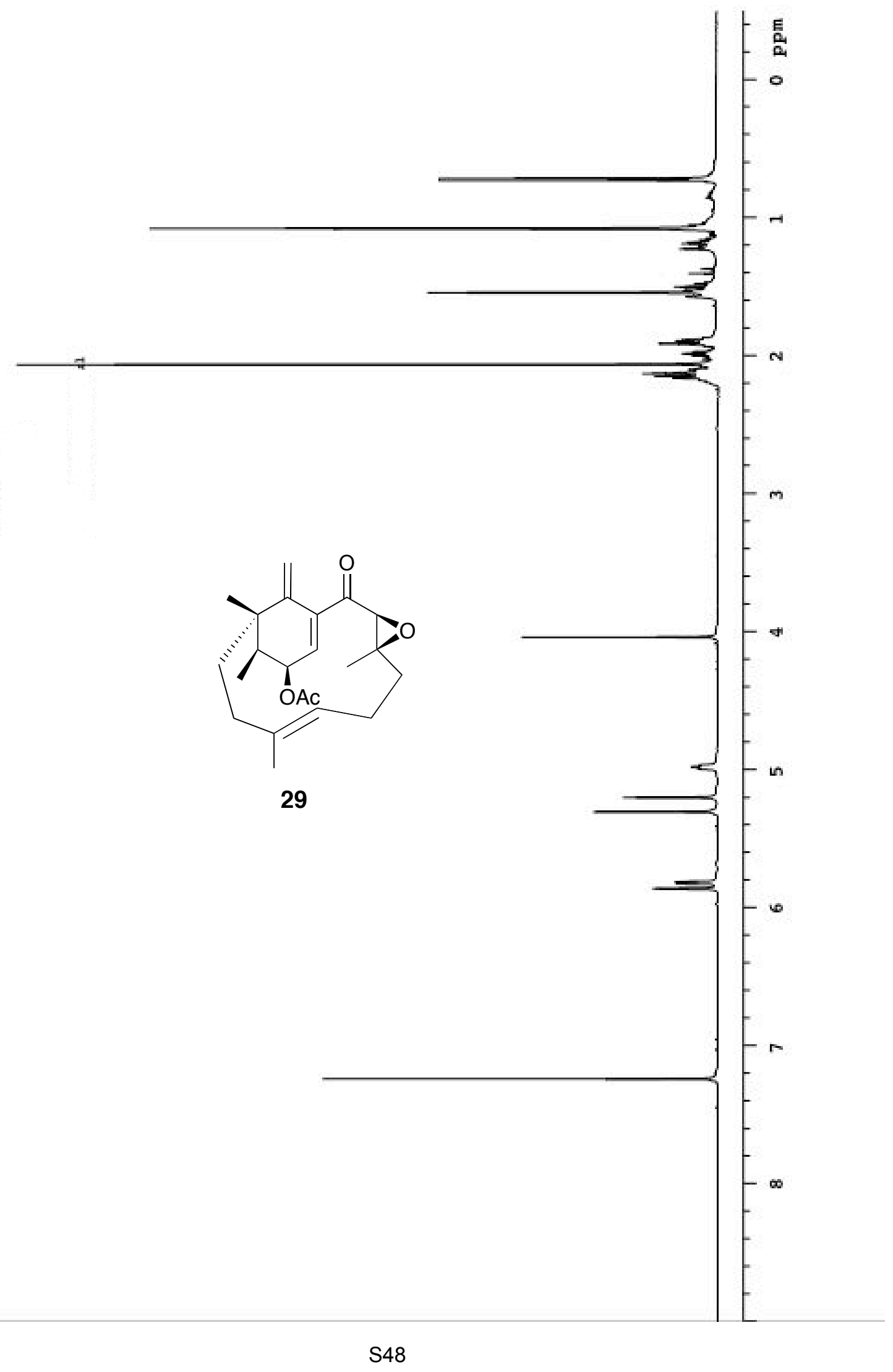




$$
\neq
$$




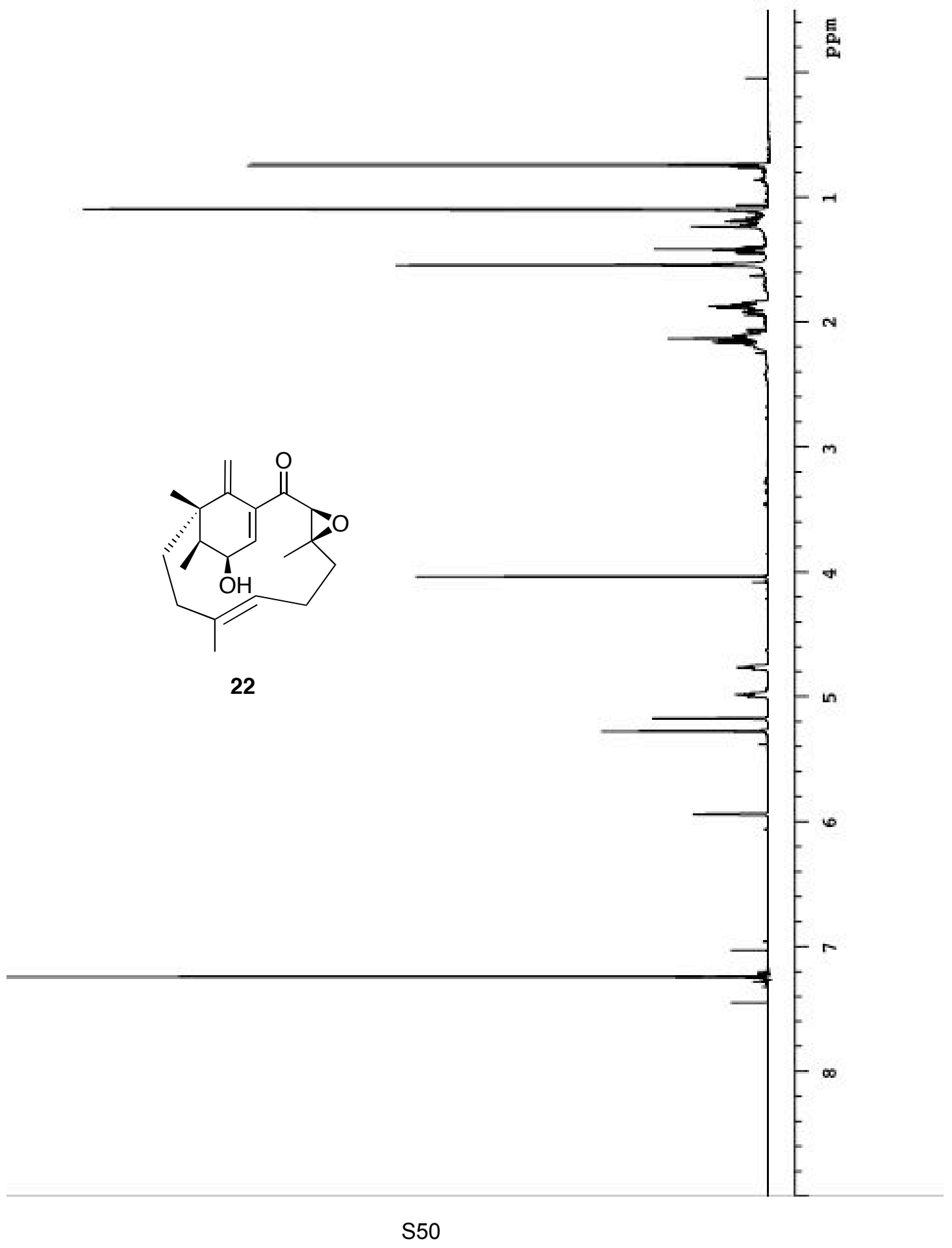




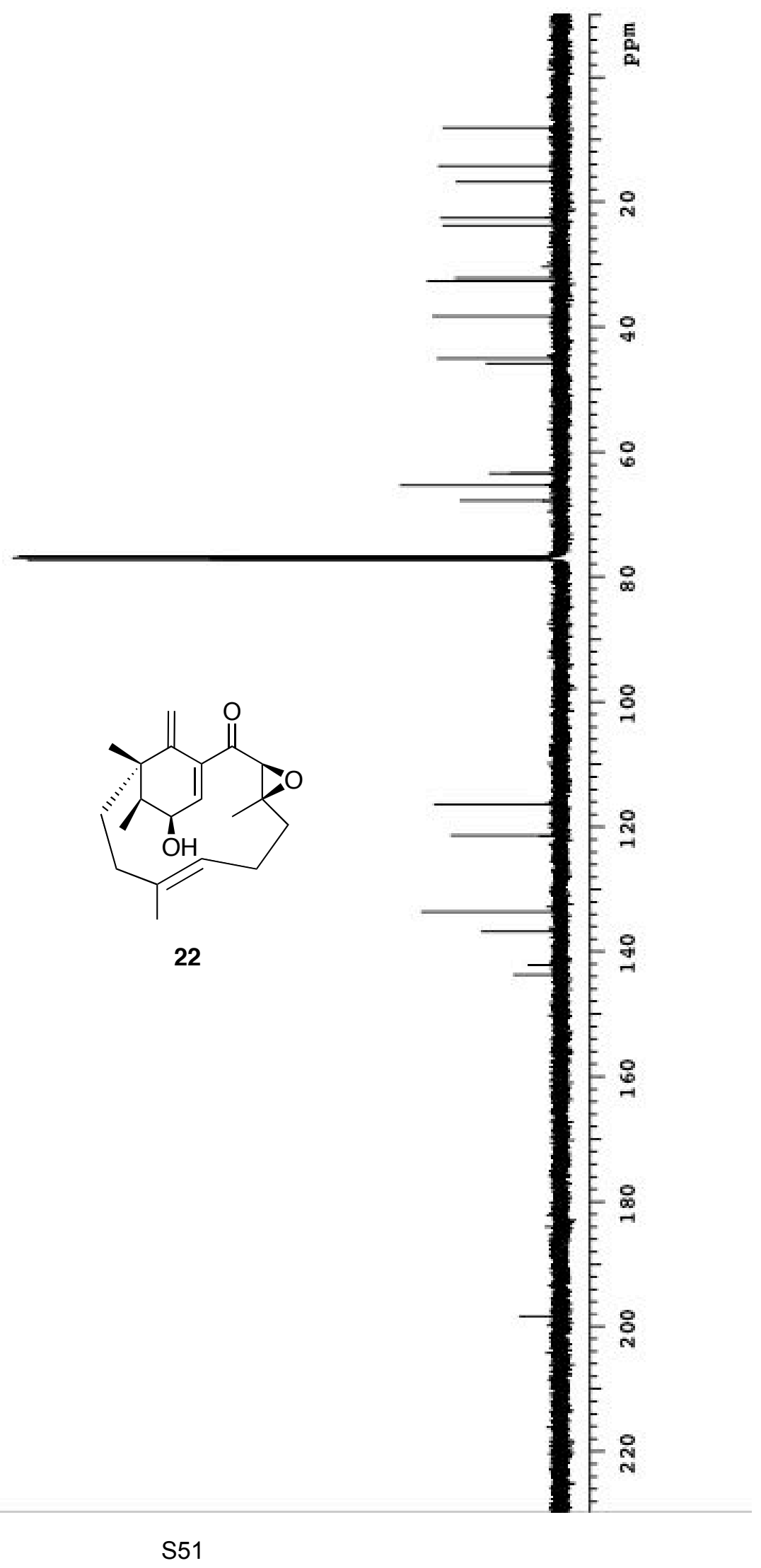




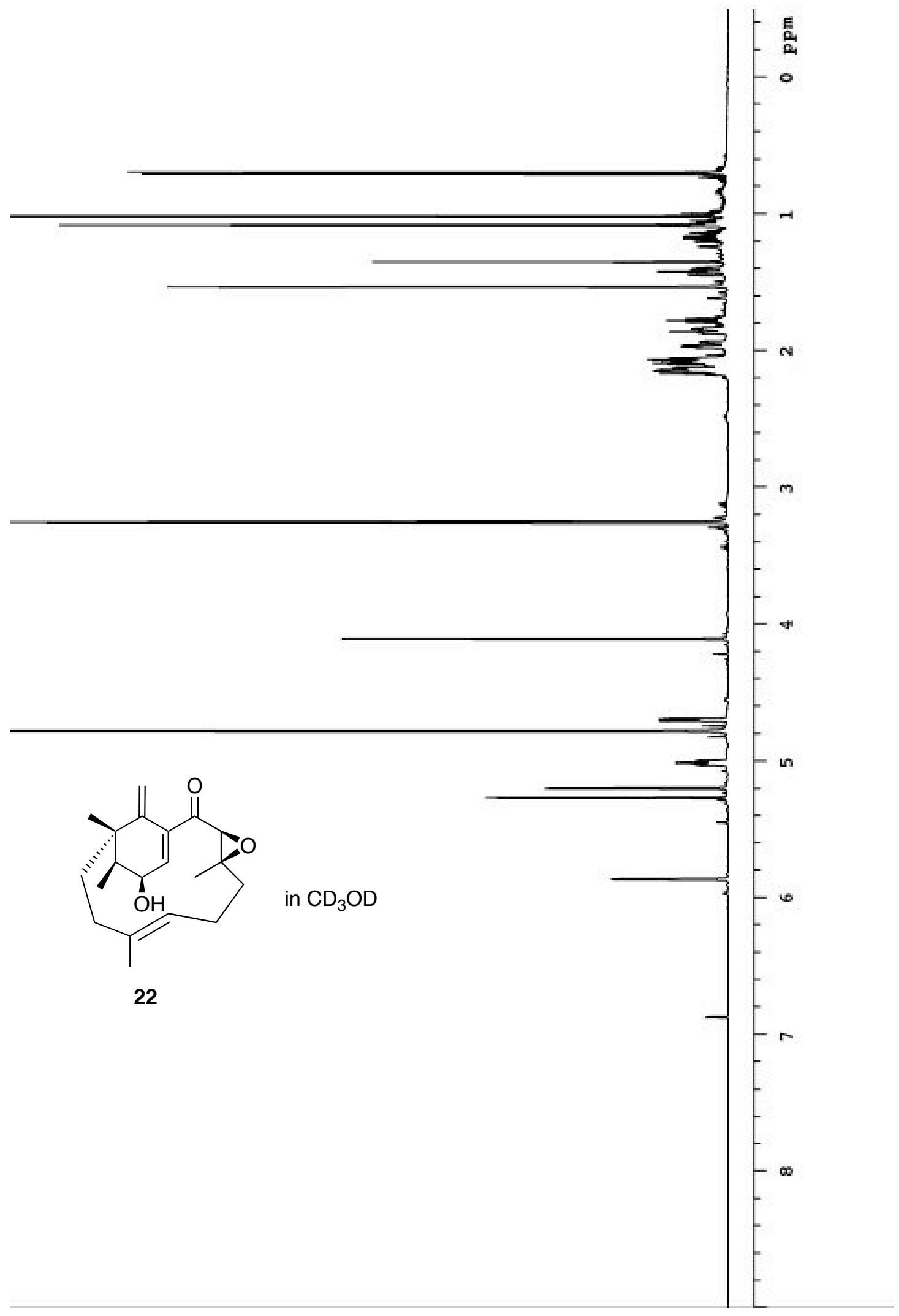




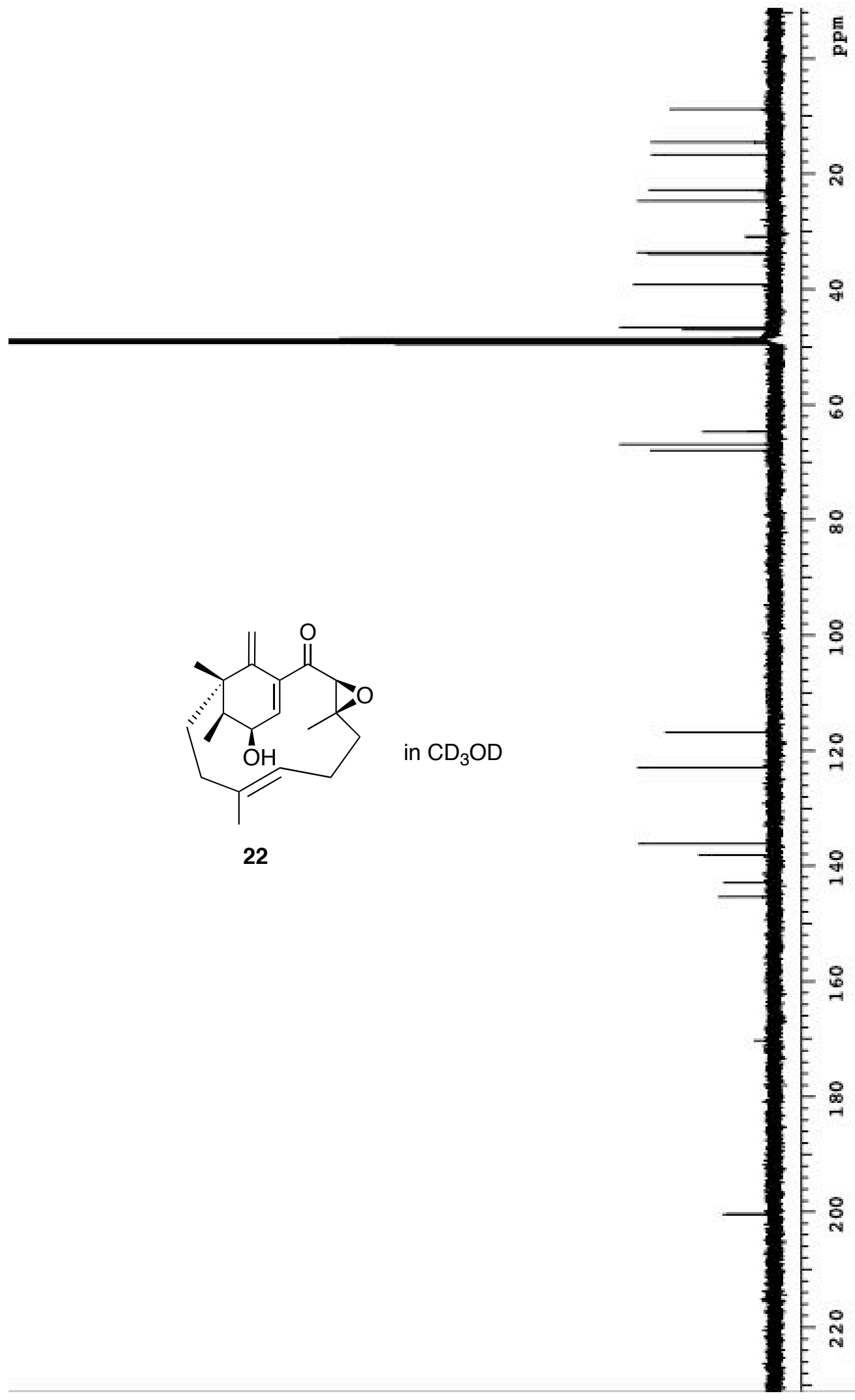




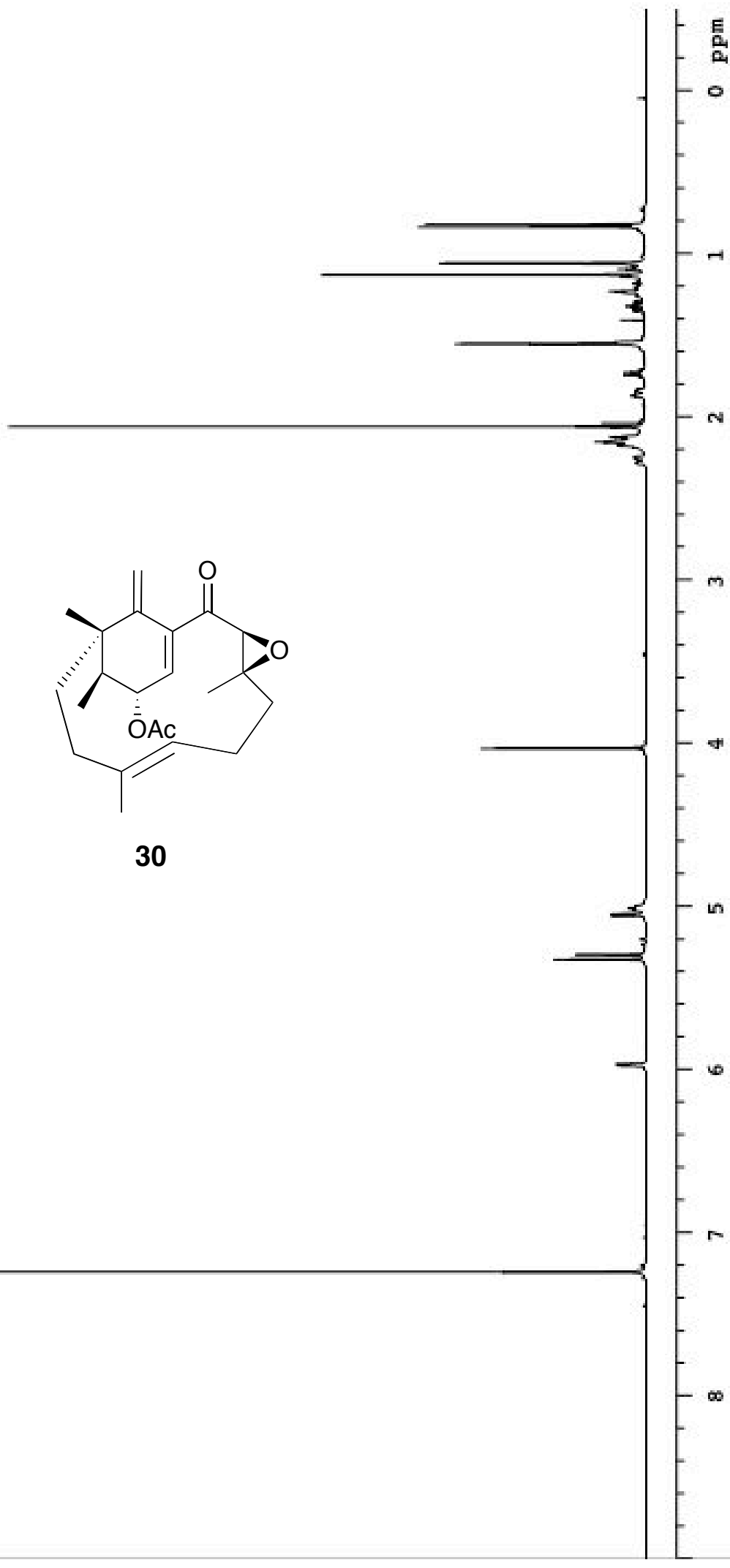




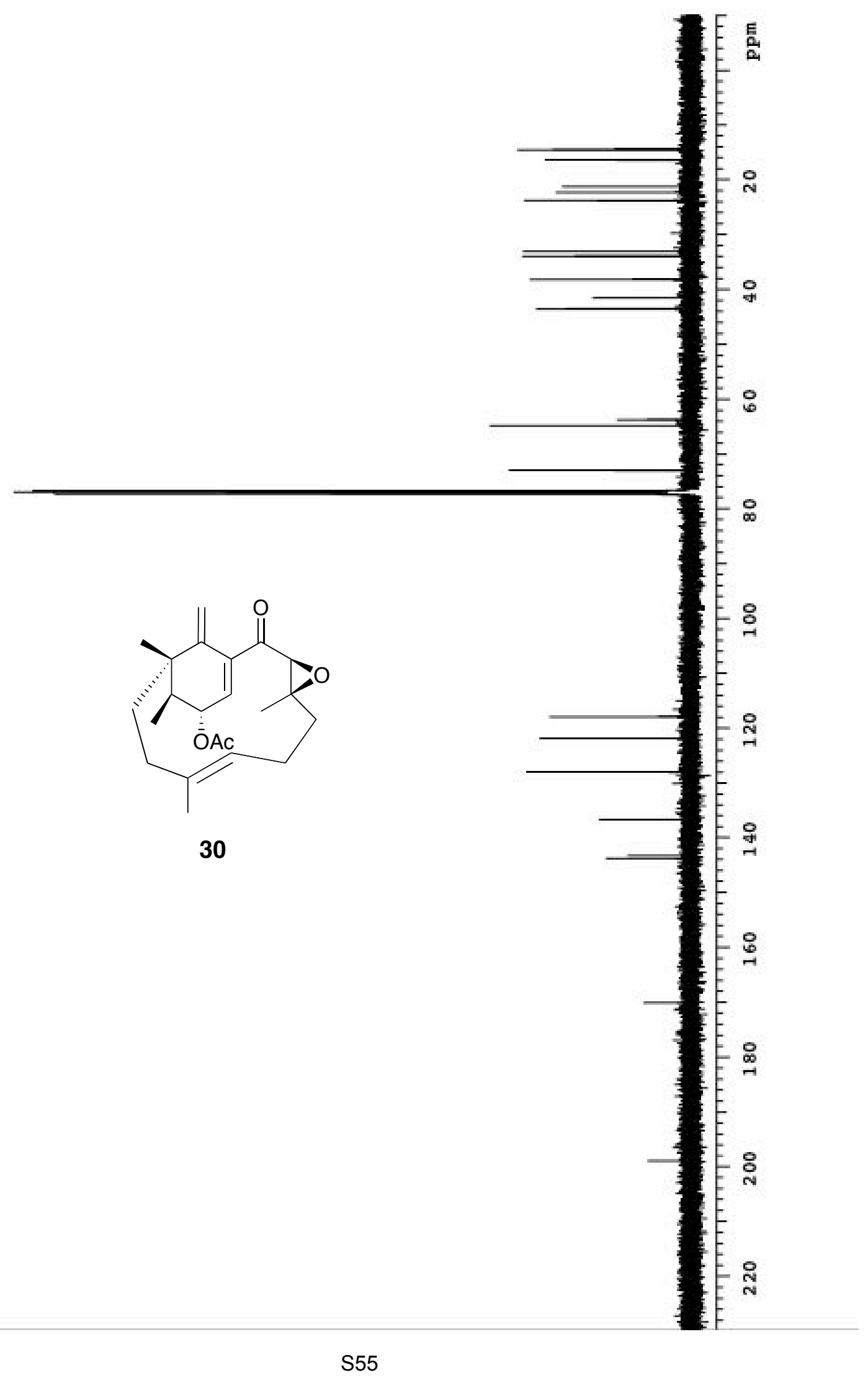




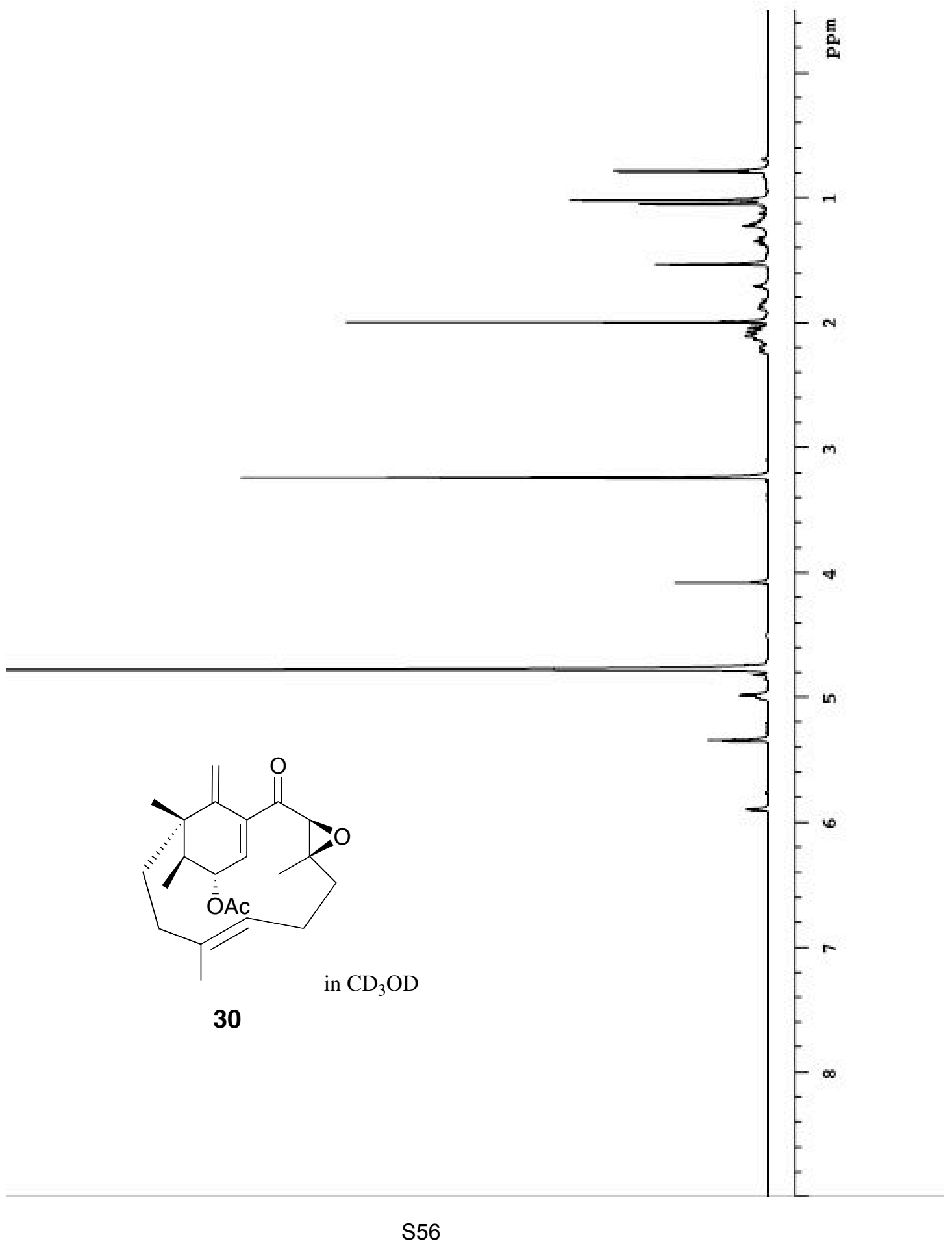




$$
1
$$




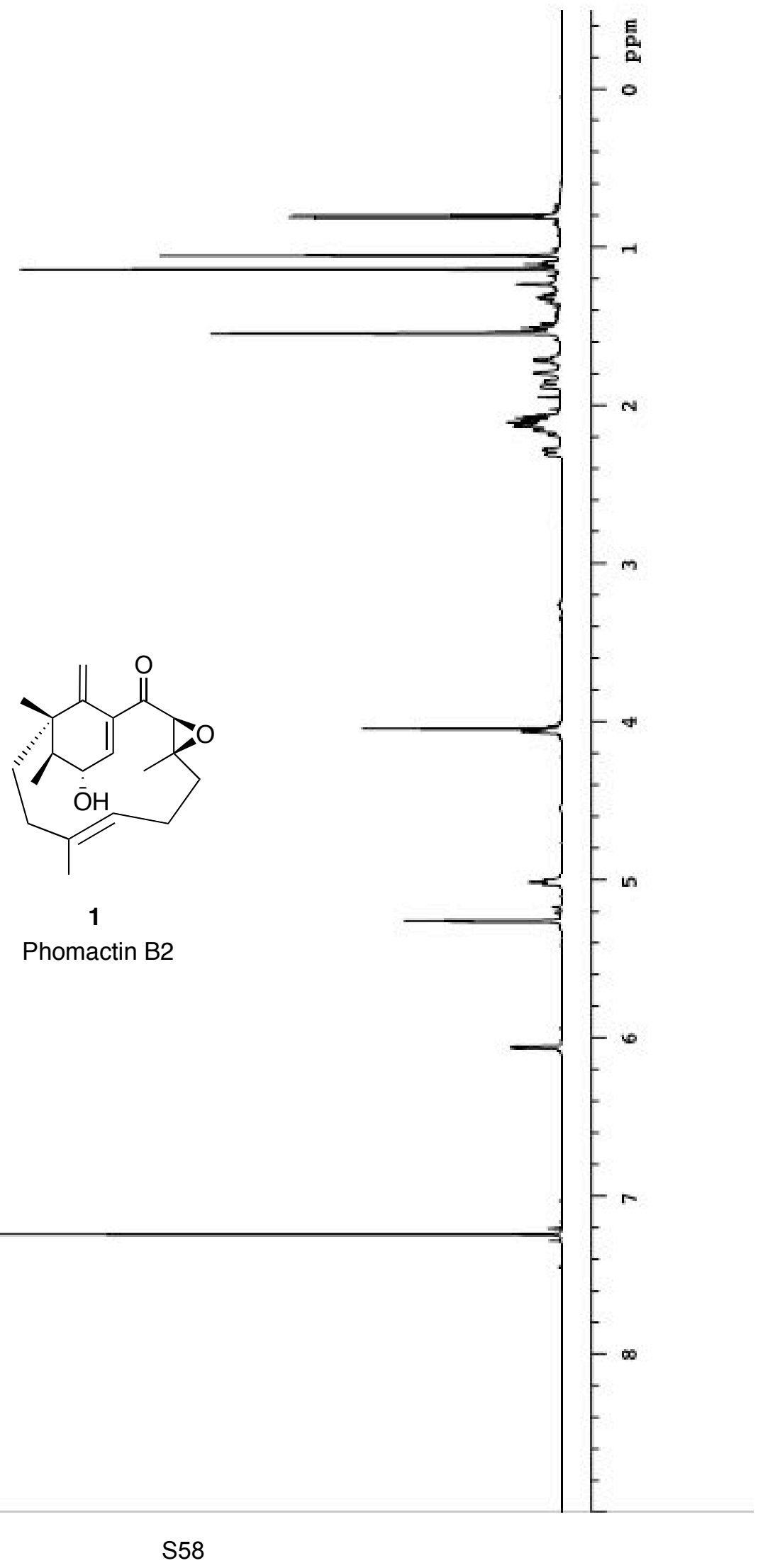




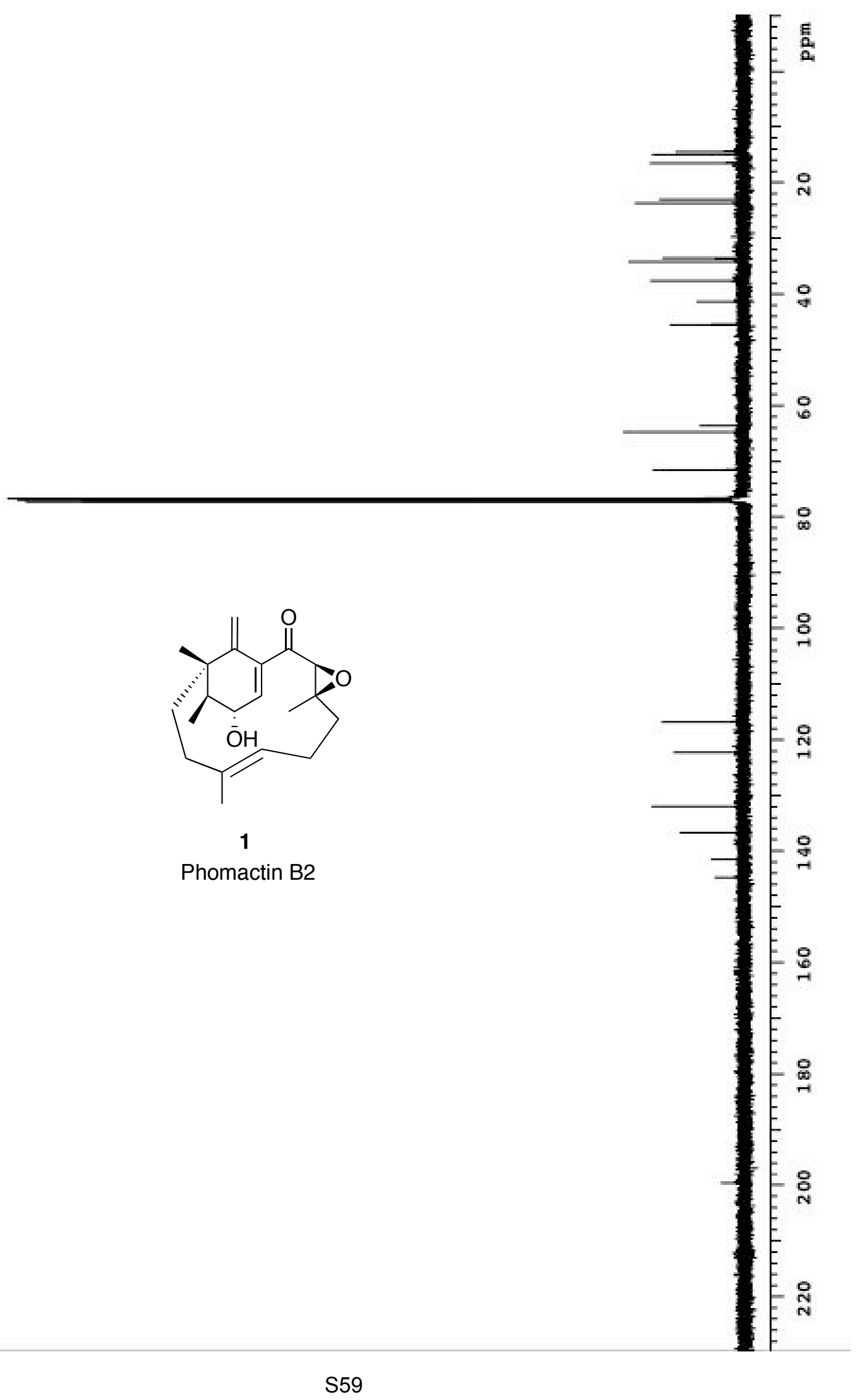




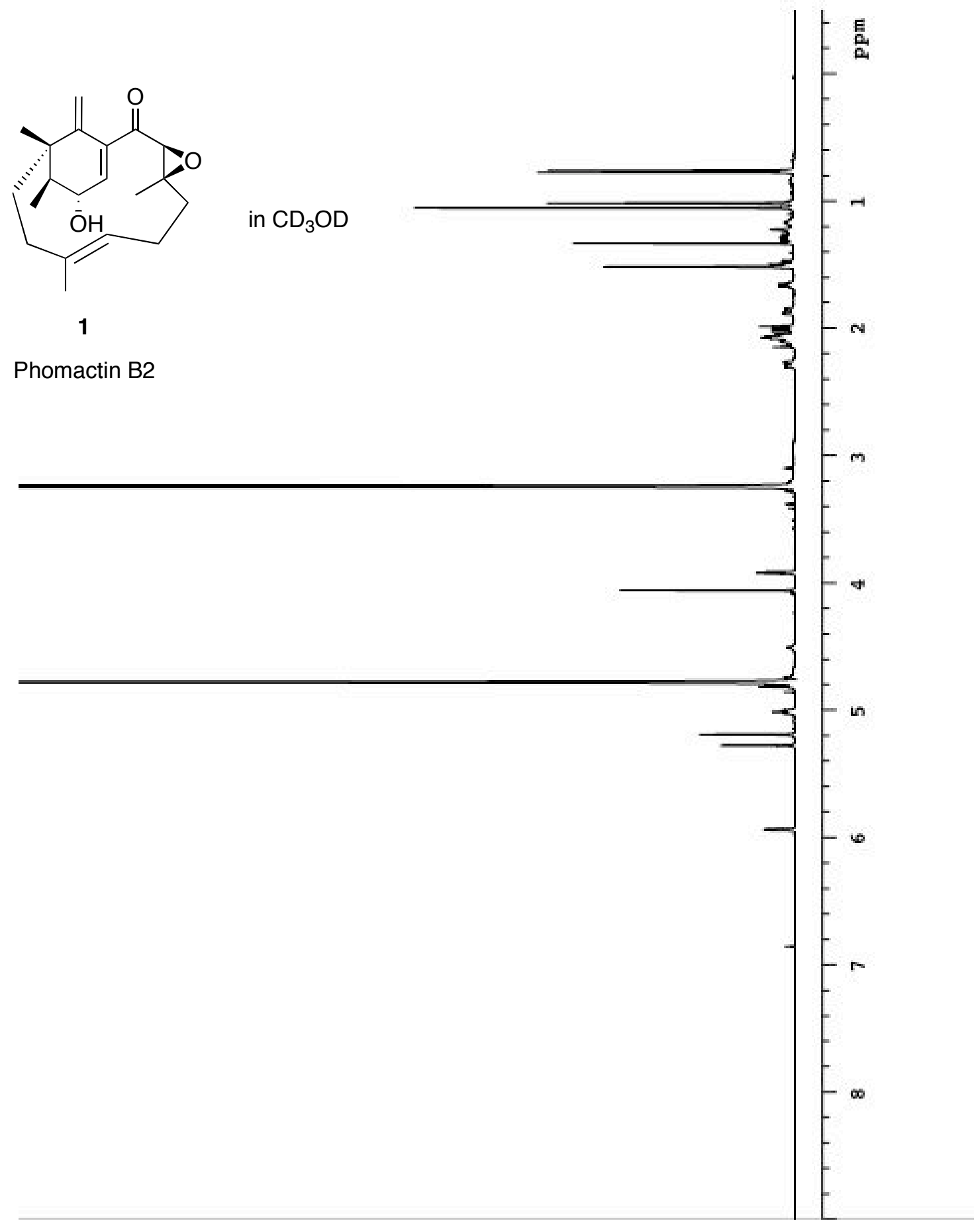




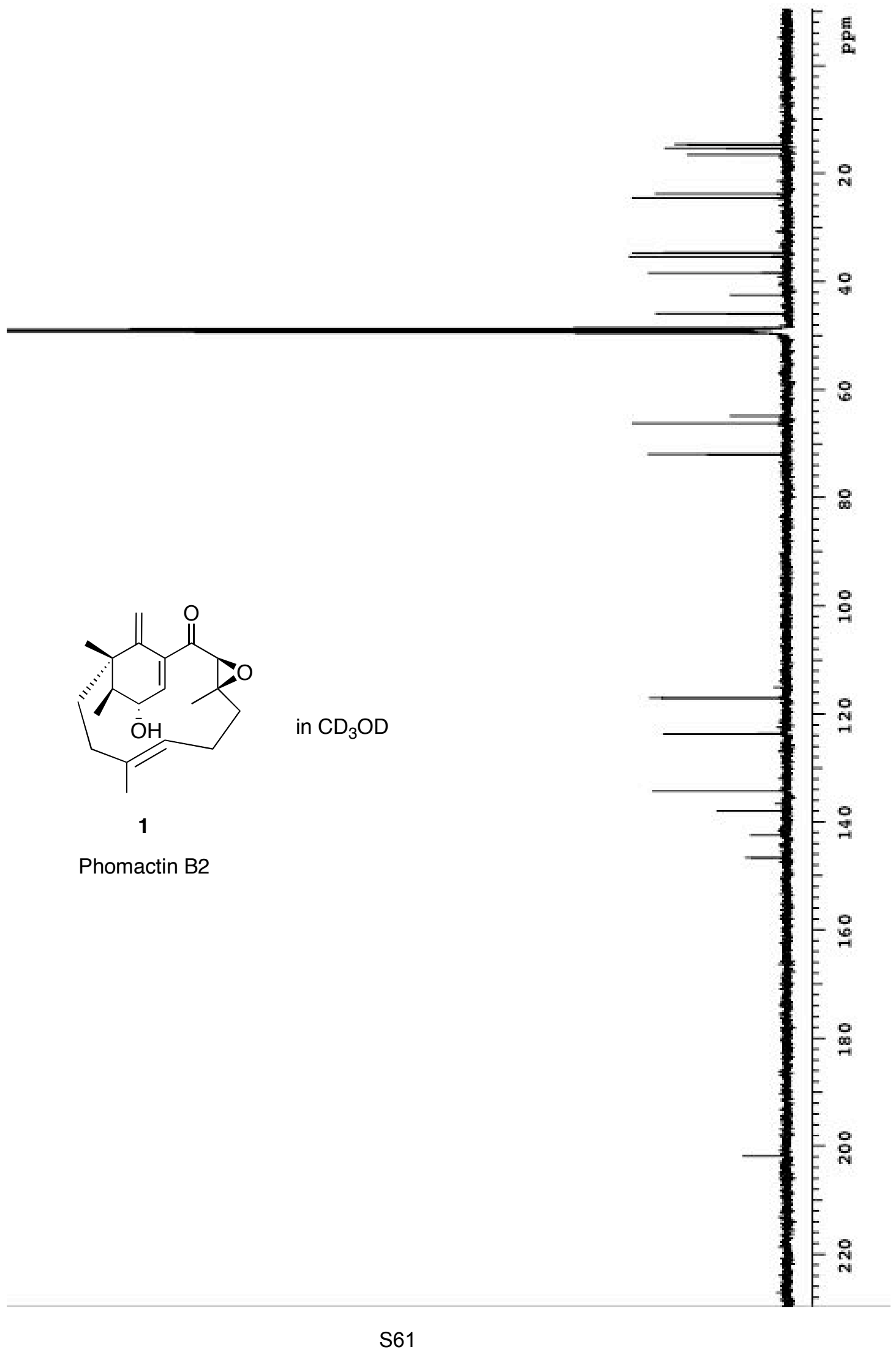




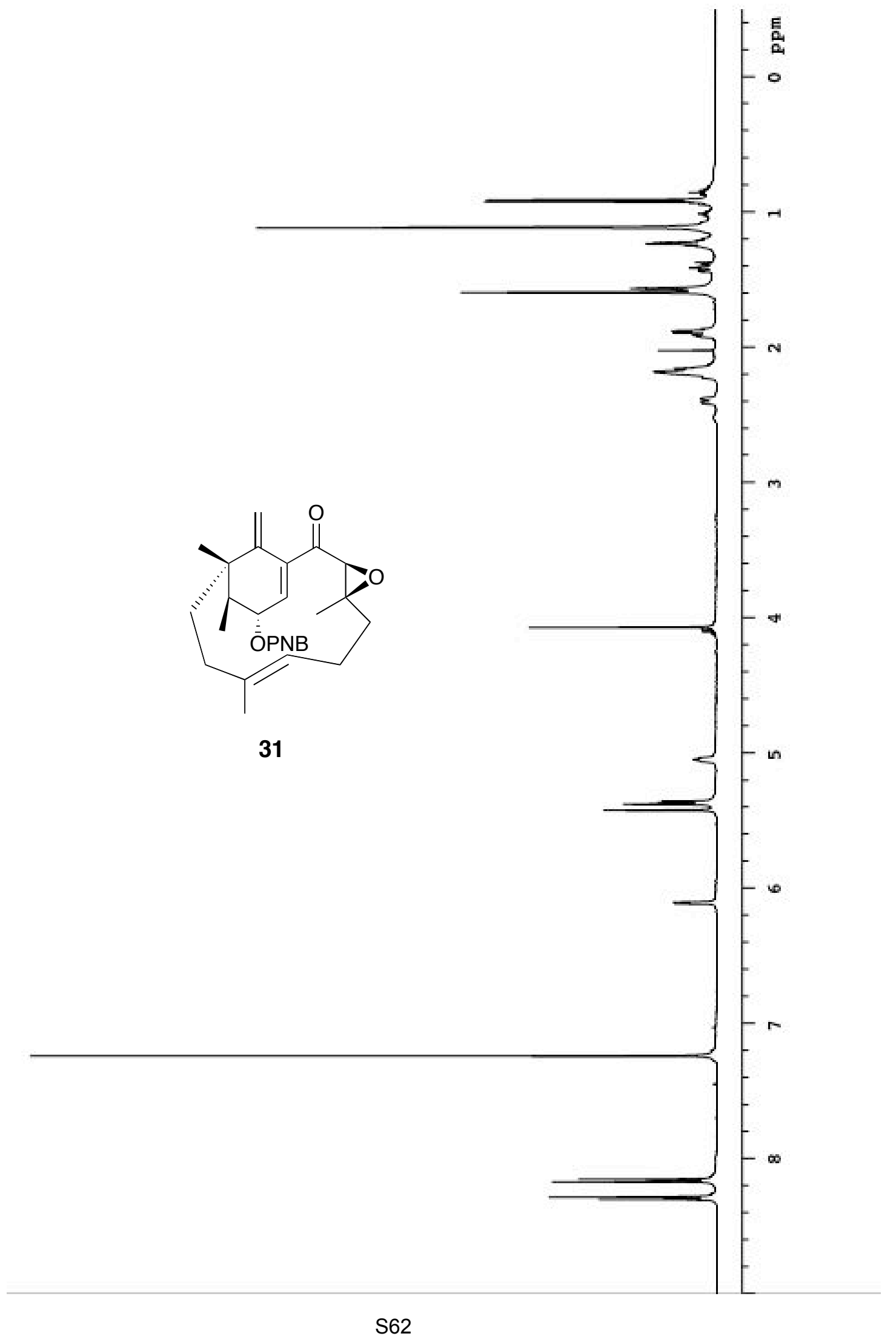




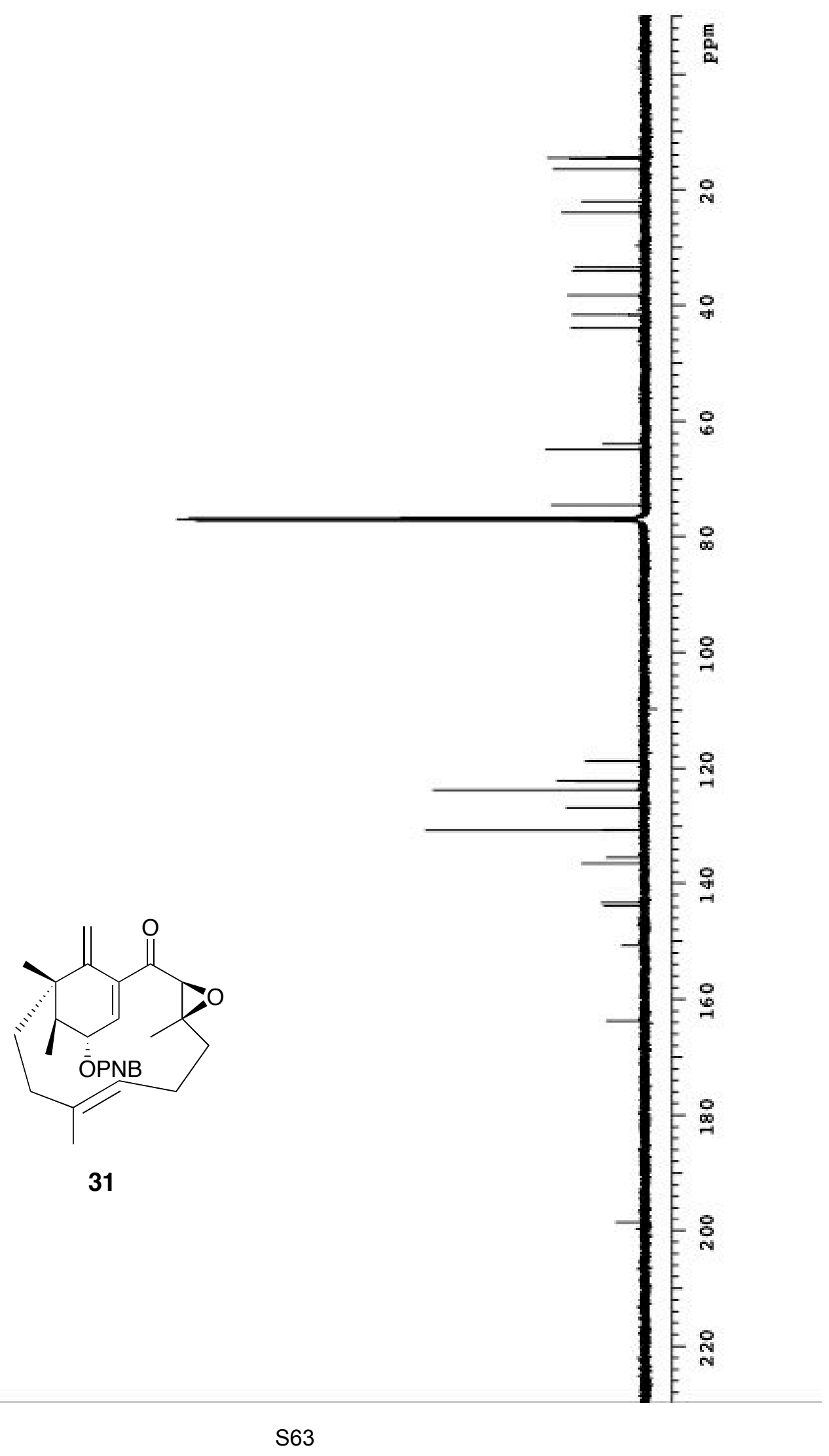

